\title{
Review
}

\section{Nucleotide-binding oligomerization domain 1 and gastrointestinal disorders}

\author{
By Tomohiro Watanabe, ${ }^{* 1, * 2, \dagger}$ Naoki Asano, ${ }^{* 3}$ Masatoshi KUdo*1 and Warren StrobeR ${ }^{* 2}$
}

(Communicated by Shizuo AKIRA, M.J.A.)

\begin{abstract}
Nucleotide-binding oligomerization domain 1 (NOD1) is an intracellular sensor that detects small peptides derived from the cell wall component of intestinal microflora. NOD1 is expressed in both non-hematopoietic cells such as epithelial cells and hematopoietic cells such as antigen-presenting cells. Detection of its ligand by NOD1 leads to innate immune responses through activation of nuclear factor kappa B and type I interferon as well as induction of autophagy. Innate immune responses through NOD1 activation play an indispensable role both in host defense against microbial infection and in the development of gastrointestinal disorders. Of particular importance, NOD1-mediated innate immune responses are associated with mucosal host defenses against Helicobacter pylori (H. pylori) infection of the stomach and with the development of pancreatitis. In this review, we discuss the molecular mechanisms by which NOD1 activation leads to the development of $H$. pylori-related gastric diseases and pancreatitis.
\end{abstract}

Keywords: NOD1, Helicobacter pylori, pancreatitis

\section{Introduction}

Over the past several decades, our understanding of innate immune system responses has been markedly increased through the intensive study of Toll-like receptors (TLRs). ${ }^{1}$ ) The TLR system consists of a family of recognition units that respond to microbe-associated molecular patterns (MAMPs) derived from microbes and that are expressed on the cell-surface or endosomes of innate immune cells such as epithelial cells and antigen-presenting

*1 Department of Gastroenterology and Hepatology, Kindai University Faculty of Medicine, Osaka-Sayama, Osaka, Japan.

*2 Mucosal Immunity Section, Laboratory of Host Defenses, National Institute of Allergy and Infectious Diseases, National Institutes of Health, Bethesda, MD, U.S.A.

*3 Division of Gastroenterology and Hepatology, Tohoku University Graduate School of Medicine, Sendai, Miyagi, Japan.

$\dagger$ Correspondence should be addressed: T. Watanabe, Department of Gastroenterology and Hepatology, Kindai University Faculty of Medicine, 377-2 Ohnohigashi Osaka-Sayama, Osaka 589-8511, Japan (e-mail: tomohiro@med.kindai.ac.jp).

Abbreviations: Ag: antigen; AMP: anti-microbial peptide; APC: Antigen presenting cell; ATF6: activating transcription factor 6; CagA: cytotoxin-associated gene A; CARD: caspase activation and recruitment domain; CCKR: cholecystokinin receptor; CCL2: C-C motif chemokine ligand 2; CCR2: C-C chemokine receptor type 2 ; $\mathrm{Cdx} 2$ : caudal-type homeobox protein 2 ; cIAP: cellular inhibitor of apoptosis protein; CXCL: C-X-C motif cells (APCs). Activation of TLRs generally leads to pro-inflammatory cytokine responses and enhanced antigen (Ag)-specific adaptive immune responses, both of which are necessary for host defense against microbial infections. ${ }^{1)}$ However, in some circumstances such activation can be inappropriate or excessive and in these instances has been implicated in the immuno-pathogenesis of auto-immune diseases. $^{2)}$

More recent studies of innate immune responses have led to the discovery that the TLR-dependent

chemokine ligand; DAMP: damage-associated molecular pattern; iE-DAP: $\gamma$-D-glutamyl meso-diaminopimelic acid; ER: endoplasmic reticulum; GI: gastrointestinal; H. pylori: Helicobacter pylori; IKK $\varepsilon$ : I $\kappa$ B kinase $\varepsilon$; IRE1: Inositol-requiring enzyme 1; IRF: interferon regulatory factor; ISGF3: IFN-stimulated gene factor 3; LPS: lipopolysaccharide; LRR: leucine rich repeat; LUBAC: linear ubiquitin chain assembly complex; Lysine: K; MAMP: microbeassociated molecular pattern; MAPK: mitogen activated protein kinase; NOD: nucleotide-binding oligomerization domain; NF$\kappa \mathrm{B}$ : nuclear factor- $\kappa \mathrm{B}$; NLR: NOD-like receptor; OMV: outer membrane vesicle; PERK: protein kinase RNA-like endoplasmic reticulum kinase; PGN: peptidoglycan; PKC: protein kinase C; SLC15: solute carrier family 15; Stat: signal transduction and activator of transcription; TAK1: TGF- $\beta$-activated kinase 1 ; TBK1: TANK-binding kinase 1; Th1: T helper type 1; TLR: Toll-like receptor; TRAF: TNF receptor associated factor; T4SS: type IV secretion system; UPR: unfolded protein response; XIAP: $\mathrm{X}$-linked inhibitor of apoptosis. 
model of host recognition and response to MAMPs described above are not limited to TLRs. This became apparent from the identification of another family of innate immune receptors called nucleotidebinding oligomerization domain (NOD)-like receptors (NLRs) that also recognize and respond to MAMPs ${ }^{3-6)}$ but differ from TLRs in their structure and in their cytosolic location. In addition, the MAMPs sensed by TLRs and NLRs are markedly different, as is the downstream signaling pathways induced by the MAMPs. ${ }^{1,3)-6)}$ These differences make it clear that NLRs constitute an innate immune mechanism that is parallel to but independent of the TLRs mechanism.

NOD1 is a prototypical NLR that detects small peptides (notably $\gamma$-D-glutamyl meso-diaminopimelic acid (iE-DAP) and related peptides) derived from peptidoglycan (PGN), a major component of the bacterial cell wall. ${ }^{7)}$ Given the fact that PGN containing iE-DAP is present in the cell wall of the Gram-negative bacteria constituting the major class of organisms comprising the gut microflora, NOD1 responses are potentially involved in both homeostatic and host-defense responses to commensal and pathogenic organisms in the gastrointestinal (GI) tract. In fact, there is extensive evidence that NOD1 responses to commensal organisms are not only important during the development of the mucosal immune system early in life, ${ }^{8)}$ but also important later on in responses to infection caused by important pathogens such as Helicobacter pylori (H. pylori).${ }^{9)-11)}$ In addition, there is evidence that NOD1 responses are key factors in the development of pancreatitis as reflected in the experimental pancreatitis caused by cholecystokinin hyperstimulation. ${ }^{12)-14)}$ In this review, we focus on these somewhat disparate NOD1-mediated responses with the aim of clarifying how molecular events initiated by NOD1 activation can contribute to both host defense and inflammatory responses.

\section{Structure of NOD1 and uptake of NOD1 ligands}

NOD1 is structurally similar to other NLR proteins in that it is composed of an N-terminal caspase activation and recruitment domain (CARD), a central NOD and a C-terminal leucine-rich repeat domain (LRR). ${ }^{3)-6)}$ As in the case of TLRs containing LRR domains, NOD1 detects its ligand through its C-terminal LRR and ligand binding to this domain leads to oligomerization of NOD1 accompanied by binding and activation of receptor interacting protein
2 (RIP2), the obligate initiator of NOD1 downstream signaling pathways.

Given the fact that NOD1 is expressed in the cytoplasm rather than in the membrane of cells, bacterial PGN needs to gain entry into cells before it can activate NOD1. Obviously, this problem does not apply to ligand associated with invasive bacteria that exhibit various mechanisms of cell entry. However, there exist other pathways of ligand entry that can be potentially used by non-invasive bacteria as well as invasive bacteria. One such pathway involves cellular uptake of bacteria by endocytosis followed by degradation of bacterial components (including PGN) in phago-lysosomes and transport of the peptides derived from degradation across the endosomal membrane by a peptide transporter protein, solute carrier family 15 (SLC15A3 and/or SLC15A4) members. ${ }^{15), 16)}$ This has been shown by the fact that SLC15A4-deificent mice showed a significant decrease in the NOD1 ligand-induced secretion of cytokine as compared with SLC15A4intact mice ${ }^{15)}$ and SLC15A3-deficient cells have been shown to exhibit reduced production of cytokines upon stimulation with NOD2 ligand. ${ }^{16)}$ Interestingly, NOD2 binds to SLC15A and the complex formed includes RIP2, indicating that the transporter protein serves as a "platform" for NOD protein activation at the endosomal interface. Another pathway of NOD1 ligand delivery into the cytoplasm involves outer membrane vesicles (OMVs), i.e., bilayered spherical structures that can be shed from all Gram-negative bacteria. ${ }^{17)}$ Such OMVs contain PGN and are taken up by cells via autophagy into autophagosomes. NOD1 ligand is presented to NOD1 by early endosomes, perhaps by a mechanism involving SLC15 transporter proteins as discussed above; this mechanism whatever its nature, also facilitates NOD1 binding to RIP2. Yet a third pathway of NOD1 ligand delivery occurs via direct delivery of ligand by a Type IV bacterial secretion system. ${ }^{9)}$ This has been described in relation to delivery of PGN into gastric epithelial cells by $H$. pylori bearing the cag pathogenicity island, the latter encoding the genes for the secretion system. However, it applies to any bacterium that expresses a Type IV secretion system.

These findings regarding the delivery systems of NOD1 ligands and PGN strongly suggest that NOD1 can recognize not only invasive bacteria but also extracellular bacteria. As such they suggest that activation of NOD1 is a common event in cells exposed to Gram-negative bacteria. 


\section{NOD1-expressing cells}

NOD1 is expressed in a broad range of both hematopoietic cells and non-hematopoietic cells and thus has the potential to fulfill a variety of immunologic functions. Among hematopoietic cells its role in the innate responses of APCs such as macrophages and dendritic cells is most prominent and indeed these cells constitutively express cytoplasmic NOD1 that mediate cytokine responses to NOD1 ligands as already indicated above. ${ }^{3)-6)}$ However, while independent NOD1 ligand stimulation elicits rather low level cytokine responses as compared to those elicited by TLR ligands they have a marked ability to enhance concomitant TLR responses. ${ }^{18), 19)}$ This is most likely due to the fact that NOD1 signaling (as well as NOD2 signaling) engages a down-stream activation pathway that is somewhat independent of and additive to the pathway ordinarily utilized by TLR signaling, such as RIP2 signaling. ${ }^{3)-6)}$ Whatever its underlying mechanism, the synergism between NOD1 and TLR signaling has been shown to be necessary for the initiation of substantial adaptive $\mathrm{T}$ helper type 1 (Th1), Th2, and Th17 responses. ${ }^{20), 21)}$ In effect, this means that innate immune sensing of PGN by NOD1 acts cooperatively with sensing of MAMPs by TLRs to promote the development of the robust innate and adaptive responses necessary for eradication of invasive bacteria. A good example of this is the role of NOD1 in a model of Salmonella typhimurium infection wherein it has been shown that NOD1 expressed by intestinal lamina propria dendritic cells is indispensable to the elimination of the Salmonella. ${ }^{22)}$

Another role of cytosolic NOD1 in microbial infection also related to the fact that its signaling pathway is somewhat independent of that utilized by TLR ligands has been uncovered by Kim et al. ${ }^{23), 24)}$ It has been shown that repeated exposure of APCs to the same or other TLR ligands results in reduced proinflammatory cytokine responses and defense against bacteria, probably due to an as yet poorly defined tolerance mechanism. ${ }^{25)}$ However, such reduction is more severe in the absence of NOD1 (and NOD2), indicating that responses mediated by the latter ameliorate the tolerance effect. ${ }^{23), 24)}$ This can be explained by the supposition that mechanisms of TLR and NOD tolerization are different and that NOD responses are preserved in the face of TLR tolerization.

NOD1 (and NOD2) are also expressed by B and $\mathrm{T}$ cells but ligands for these innate factors elicit responses only when the cells are also stimulated via their respective Ag receptors. ${ }^{26), 27)}$ However, the costimulatory responses to NOD1 and NOD2 ligand stimulation in these cells are quite modest and are observed with respect to NOD1 only in the case of tonsil-derived B cells.

Neutrophils are yet another hematopoietic cell that expresses functional NOD1 and indeed it has been shown that bone marrow neutrophils are preactivated by NOD1 (but not by NOD2) recognition of bacterial PGN translocated from the gut into the bone marrow. ${ }^{28), 29)}$ In addition, such NOD1-mediated neutrophil pre-activation and its associated increased phagocytic capacity enhances killing of Streptococcus pneumoniae and Staphylococcus aureus organisms and thus participates in host defense against infection with these bacteria.

As indicated above, NOD1 is also expressed in non-hematopoietic cells and indeed NOD1 responses in such cells may contribute to homeostasis or host defense against pathogens in a manner independent of concomitant NOD1 responses in APCs. This is usually inferred from in vitro studies of cell lines or in vivo studies of in situ cells that are shown to produce NOD1-dependent, epithelial cell-specific anti-microbial peptides (AMPs). NOD1 responses in gut epithelial cells have been the main focus of study in this context corresponding to the fact that such cells are in constant contact with the gut microflora that express NOD1 ligands. ${ }^{3-6)}$ With respect to gut epithelial cell responses affecting homeostasis, it has been shown that NOD1-deficient mice (as well as NOD2-deficient mice) exhibit increased para-cellular permeability as well as decreased RegIII- $\gamma$ production and, as a possible consequence, exhibit increased susceptibility to dextran sodium sulfate-induced colitis. ${ }^{30)}$ In addition, qPCR-based assessment of mRNA expression in the ileum or cecum of NOD1deficient mice revealed that such mice produced lower levels of NOD2, Muc2, $\alpha$ - and $\beta$-defensins as well as keratinocyte-derived chemokine as compared to NOD1-intact littermates; however, this was not associated with changes in the gut microbiome. ${ }^{31)}$ These studies relate to those of NOD2-deficient mice in which it was shown that NOD2 deficiency leads to increased gut permeability, increased microfloradependent induction of suppressor cells and decreased experimental colitis; thus, NOD2 deficiency (and by extension, NOD1 deficiency) has significant down-stream effects on gut homeostasis. ${ }^{32)}$

Epithelial cell-intrinsic NOD1 responses also contribute to host defense against gut pathogens. 
Thus, H. pylori, an organism that does not invade the lamina propria, elicits a NOD1-dependent type I IFN and chemokine responses in epithelial cell lines. ${ }^{9), 10)}$ That this type of response affects host defense was shown by the fact that the gastric cancer cell line with reduced NOD1 expression secrete a reduced amount of AMPs and exhibited a reduced capacity to kill H. pylori organisms; ${ }^{33)}$ in addition, mice with NOD1 deficiency exhibit increased susceptibility to $H$. pylori infection due to impaired type I IFN and Th1 responses. ${ }^{34)}$ Such NOD1-mediated host defense is not limited to $H$. pylori since it has been shown that exposure of cells to enteroinvasive Escherichia coli elicits a NOD1-dependent host defense response suggesting that NOD1 signaling in epithelial cells has a very broad capacity to induce host defense factors. ${ }^{35)}$ Finally, it should be mentioned that NOD1-deficient mice are more susceptible to Clostridium difficile infection which in this case was attributed to decreased neutrophil recruitment occurring as a result of decreased epithelial cell $\mathrm{C}-\mathrm{X}-\mathrm{C}$ motif chemokine ligand 1 (CXCL1) production. ${ }^{36)}$

NOD1 signaling relating to host defense is by no means limited to epithelial cells in the GI tract. This is shown in studies of Chlamidia trachomatis infection wherein it has been shown that host defense against infection of the female genital tract by this organism is accompanied by NOD1-mediated induction of IL- $1 \beta$ by trophoblast cells. ${ }^{37)}$ In addition, Chlamydia pneumoniae infection elicits NOD1 activation followed by IL-8 production in endothelial cells that in this case links NOD1 activation with the development of vascular lesions and coronary heart disease caused by this organism. ${ }^{38)}$ Finally, it should be noted that parenchymal cells such as hepatocytes $^{39)}$ and pancreatic acinar cells express functional NOD $\left.1 ;{ }^{12}-14\right)$ in the latter case, sensing of commensal organism-derived PGN by NOD1 mediates acute and chronic pancreatitis as discussed in greater detail below. ${ }^{12)-14)}$

The NOD1 responses of various types of cells reviewed above is to a great extent regulated by their level of NOD1 expression. As might be expected such expression is up-regulated in an inflammatory milieu such as that accompanied by the generation of type I IFN and IFN- $\gamma{ }^{40), 41)}$ The involvement of type I IFN in NOD1 expression has been inferred from studies of Listeria monocytogenes infection in which it was observed that increased macrophage NOD1 expression normally induced by this infection is virtually absent in type I IFN receptor-deficient mice. ${ }^{40)}$ On the other hand, baseline expression of NOD1 by epithelial cells is up-regulated by IFN- $\gamma$, but not TNF- $\alpha$, and this is mediated by the binding of IFN- $\gamma$ induced interferon regulatory factor 1 (IRF1) to the NOD1 promoter. ${ }^{41)}$

As mentioned above, NOD1 activation plays a protective role in a wide variety of major bacterial infections such as Salmonella typhimurium, Streptococcus pneumoniae, Staphylococcus aureus, enteroinvasive Escherichia coli, Clostridium difficile, Chlamidia trachomatis, and Chlamydia pneumoniae. ${ }^{22), 28), 29), 36)-38)}$ In addition, it is involved in the pathogenesis of several important viral infections including cytomegalovirus ${ }^{42)}$ and Hepatitis $\mathrm{C}$ virus. ${ }^{43}$ ) Thus, it is clear that NOD1 activation is involved in various kinds of human infectious diseases.

\section{Signaling pathways of NOD1 (Figure 1)}

NOD1-mediated activation of nuclear factorkappa $B(N F-\kappa B)$ and mitogen-activated protein kinases (MAPKs). NOD1 activation resulting from LRR sensing of NOD1 ligand is initiated by a NOD1 conformational change that allows a homotypic interaction between NOD1 CARD domains and NOD1 auto-oligomerization; this, in turn, is followed by recruitment of RIP2, its initial down-stream signaling molecule. ${ }^{3)-6)}$ Such RIP2 recruitment is an obligate step in NOD1 (as well as NOD2) signaling since cells from mice deficient in RIP2 are unable to mediate NOD1 (or NOD2) activation of proinflammatory cytokine responses. ${ }^{44), 45)}$ Whether RIP2 signaling is dedicated solely to NODs responses is an important question since RIP2 signaling not dependent on NODs activation may be necessary for an optimal cytokine response in the case of inflammation accompanied by both NODs and TLR stimulation. The answer to this question is somewhat controversial; thus, while earlier reports indicated that TLR responses also were mediated by RIP $2^{46)-48)}$ more recent reports indicate that TLR responses are undiminished in the absence of RIP2. ${ }^{44), 45), 49)}$ Despite these recent findings, RIP2 activation appears to be necessary for cytokine responses not stimulated by NOD1 and NOD2 since IFN- $\gamma$ responses in the absence of RIP2 are greatly diminished in Th1 cells stimulated with IL-12 or IL-12 and IL-18, ${ }^{46)}$ i.e., a cytokine response clearly not driven by NOD1 and NOD2.

Following its activation by NOD1, RIP2 in a ubiquitinated form (see below) complexes with TAK1-binding protein 2 (TAB2) and TAB3 and then recruits TGF- $\beta$-activated kinase 1 (TAK1) to form an activator of the $\mathrm{I} \kappa \mathrm{B}$ kinase (IKK) complex; 


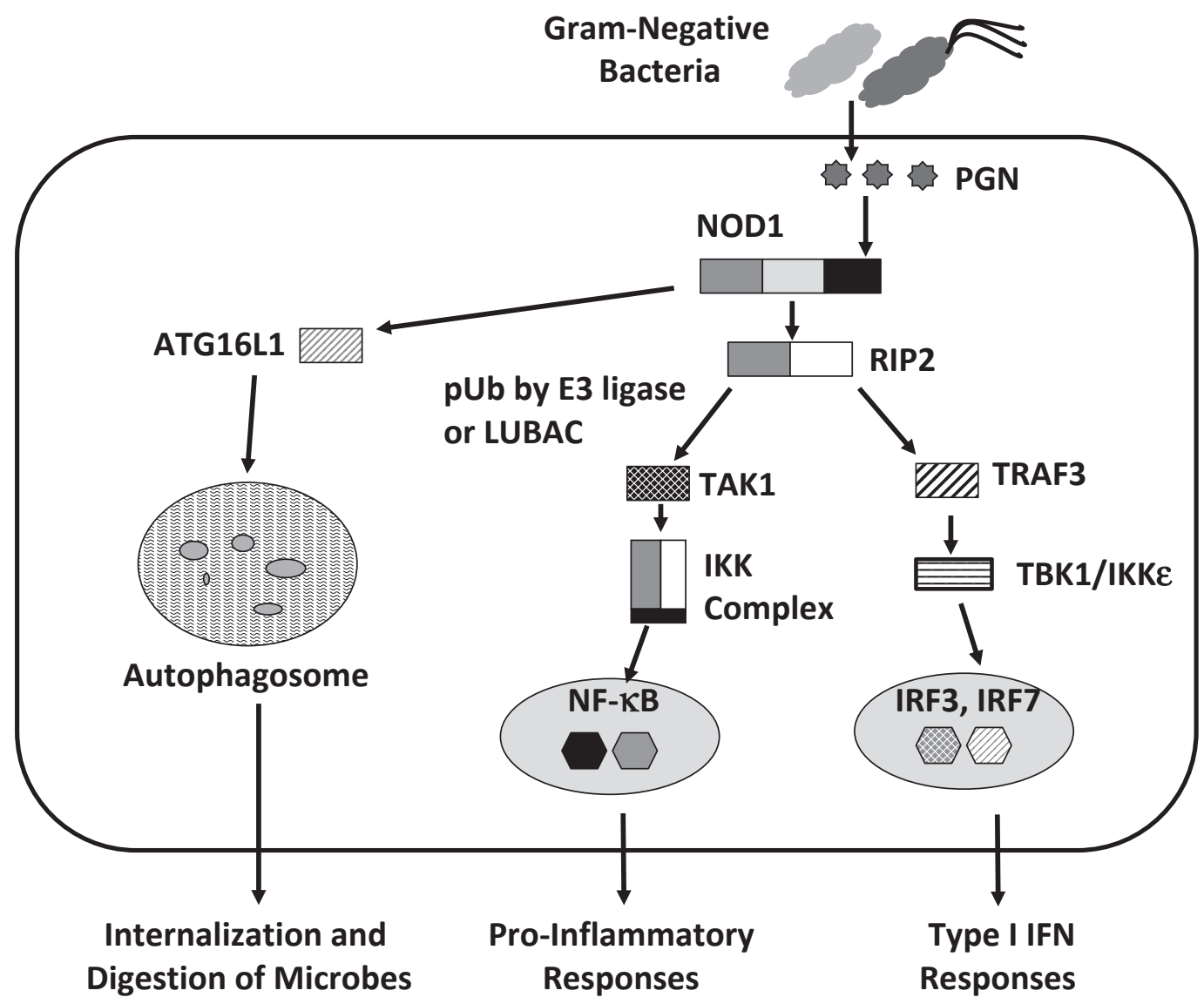

Fig. 1. Signaling pathways of NOD1. Nucleotide-binding oligomerization domain 1 (NOD1) detects peptidoglycan (PGN) derived from Gram-negative bacteria. Sensing of PGN by intracellular NOD1 leads to activation of receptor interacting protein 2 (RIP2). RIP2 subjected to poly-ubiquitination (pUb) by E3 ligases or linear ubiquitin chain assembly complex (LUBAC) interacts with TGF-betaactivated kinase 1 (TAK1) and $\mathrm{I} \kappa \mathrm{B}$ kinase (IKK) complex to induce nuclear translocation of nuclear factor- $\kappa \mathrm{B}(\mathrm{NF}-\kappa \mathrm{B})$ subunits. On the other hand the interaction between RIP2 and TNF receptor associated factor 3 (TRAF3) induces type I IFN responses through nuclear translocation of interferon regulatory factor 3 (IRF3) and IRF7. NOD1 also interacts with ATG16L1 to induce autophagy.

this, in turn, leads to the phosphorylation/degradation of $\mathrm{I} \kappa \mathrm{B} \alpha$ and nuclear translocation of nuclear factor-kappa B $(\mathrm{NF}-\kappa \mathrm{B})$ subunits that promote transcription of NF- $\kappa \mathrm{B}$ target genes through binding to multiple promoter sites. ${ }^{3)-6)}$ In addition to $\mathrm{NF}-\kappa \mathrm{B}$, mitogen-activated protein kinases (MAPKs) including extracellular signal-regulated kinase, c-JUN Nterminal kinase, and p38 are activated by RIP2. ${ }^{3)-6)}$

The binding of RIP2 to NOD1 is followed by various forms of RIP2 post-translational modification via ubiquitination. Such modification suggests that RIP2 may have various functions (depending on modification) following activation by NOD1 or that activation by NOD1 is controlled by subsequent check-points that prevents down-stream pro-inflammatory responses following inappropriate NOD1 activation.
RIP2 ubiquitination is regulated by a number of E3 ligases including various cellular inhibitor of apoptosis proteins (cIAPs) and TNF-receptor associated factors (TRAFs). ${ }^{50)}{ }^{-52)}$ E3 ligases are considered to be involved in Lysine 63 (K63)-linked polyubiquitination, acquisition of RIP2 kinase function and autophosphorylation at Tyr 474. ${ }^{50)-53)}$ More recently, X-linked inhibitor of apoptosis (XIAP) has also been shown be an ubiquitinator of RIP2. ${ }^{54)-56)}$ This IAP contrasts with the cIAPs mentioned above because it induces linear ubiquitin chain assembly (rather than K63 assembly) via recruitment of a linear ubiquitin chain assembly complex (LUBAC) composed of HOIL1L, HOIP, and SHARPIN. ${ }^{54)-56)}$ Both cIAPs-induced polyubiquitination and its accompany auto-phosphorylation and XIAP-induced polyubiquitination have been shown to be associated 
with RIP2 down-stream NF- $\kappa$ B activation, although the necessity for cIAPs-induced ubiquitination has been questioned by the fact that cIAP inhibitors do not abrogate RIP2 signaling function (see further discussion below). ${ }^{57)}$ Interestingly, mutations in the $X I A P$ gene results in an immunodeficiency state known as X-linked lymphoproliferative syndrome type $2 .{ }^{54), 55)}$ This immunodeficiency may result, at least in part, from the fact that mutations in XIAP may cause defective binding to RIP2 or ubiquitination of RIP2 and thus in defective NOD1/2-RIP2 innate responses. ${ }^{54), 55)}$

Pellino 3 and ITCH are two additional E3 ligases contributing to RIP2 polyubiquitination. Pellino 3 is a member of a ligase family known to polyubiqitinate IRAKs and thus to augment TLR signaling. ${ }^{57)}$ It induces K63 polyubiquitination of RIP2 at sites other than that targeted by cIAPs and does not act via recruitment of LUBAC. ${ }^{57)}$ Pellino 3deficient mice exhibit reduced NOD function and thus its polyubiquitination of RIP2 is thought to be necessary for NOD-mediated innate responses; in this regard, initial Pellino 3-mediated poly-ubiquitination may be necessary for subsequent XIAP polyubiquitination and the two E3 ligases may act in tandem to mediate RIP2 activation. ${ }^{57)}$ ITCH, in contrast, causes ubiquitination of RIP2 that induces reduced RIP2 activation and thus ITCH deficiency is associated with mucosal inflammation possibly due to inappropriate RIP2-mediated pro-inflammatory function. ${ }^{58)}$

The positive effect of polyubiquitinating E3ligases on RIP2 activation is counterbalanced by the negative effect of deubiquitinating enzymes that remove poly ubiquitin chains from target molecules. Thus, deubiquitinating enzymes such as A20 and CYLD are negative regulators of NOD-signaling pathways and pro-inflammatory cytokine responses are markedly increased in A20-deficient or CYLDdeficient APCs upon stimulation with NOD ligand. ${ }^{59)-61)}$ However, these deubiquitinating factors are not the only negative regulators of NODs; the latter include TRAF4 that binds directly to NOD2. ${ }^{62), 63)}$ Such negative regulators could conceivably be necessary to prevent excessive NOD inflammatory responses.

NOD1-mediated activation of type I IFN. Whereas activation of the NF- $\kappa \mathrm{B}$ and MAPK pathways are the major down-stream outcomes of NOD1 signaling, the latter also results in induction of type I IFN production, another important component of the inflammatory response. ${ }^{10), 42), 64)}$ This was initially discovered by Watanabe et al., who found that gastric and colon cancer cell lines produced a large amount of chemokines upon stimulation with NOD1 ligand and that these included chemokines with the C-X-C motif (CXCL9, CXCL10, and CXCL11) that are dependent on type I IFN responses. ${ }^{10)}$ They then found that, as expected, gastric and colonic epithelial cells stimulated with NOD1 ligand induced robust production of IFN- $\beta$ and neutralization of the type I IFN signaling pathway by blockade of the $\operatorname{IFN} \alpha \beta$ receptor resulted in a marked reduction of CXCL10 expression. $^{10)}$

Type I IFN activates transcription of genes related to anti-microbial host defenses by acting through its receptor to induce nuclear translocation of a heterotrimeric complex, called IFN-stimulated gene factor 3 (ISGF3), the latter composed of signal transduction and activator of transcription 1 (Stat1), Stat2, and IRF9. ${ }^{65)}$ Thus, in further studies relating NOD1 induction of type I IFN-induced responses to chemokine production Watanabe et al. showed that inactivation of ISGF3 via gene-silencing of Stat1 or Stat2 resulted in reduced NOD1 induction of CXCL10. Then, in studies focused on the origin of NOD1-induced CXCL10 production, Watanabe et al. conducted studies of bone marrow chimeric mice in which they showed that elevated serum levels of IFN- $\beta$ and CXCL10 seen in NOD1-intact mice treated with NOD1 ligand were markedly decreased in X-irradiated NOD1-deficient mice transplanted with NOD1-intact bone marrow cells, but not in X-irradiated NOD1-intact mice transplanted with NOD1-deficient bone marrow cells. ${ }^{10)}$ These results thus suggested that IFN- $\beta$ production followed by IFN- $\beta$-dependent chemokine responses is an innate immune response induced by NOD1 activation in non-hematopoietic cells, most likely GI epithelial cells. Given the fact that CXCL10 attracts CXCR3expressing Th1 cells, ${ }^{66)-68)}$ it is probable that activation of NOD1 signaling pathways in such epithelial cells is responsible for the generation of IFN- $\beta$ and Th1 responses.

As for the molecular mechanisms leading to IFN- $\beta$ production via NOD1 activation, detailed over-expression and knock-down studies revealed that NOD1 binding to its ligand leads to activation of RIP2 followed by the physical interaction between RIP2 and various TRAFs, such as TRAF2, TRAF5, and TRAF6 that then play a role in RIP2-mediated NF- $\kappa$ B activation. ${ }^{51), 69)}$ In addition, activated RIP2 interacts with TRAF3 to initiate a signaling pathway that results in induction of type I IFNs. ${ }^{10)}$ This 
pathway involves activation of TANK-binding kinase 1 (TBK1) and $\mathrm{I} \kappa \mathrm{B}$ kinase $\varepsilon(\mathrm{IKK} \varepsilon)$ followed by nuclear translocation of IRF7, a transcription factor acting directly as a transcription factor for type I IFN promoter and indirectly through its induction of type I IFN and the latter's induction of ISGF3. ${ }^{70), 71)}$ Thus, the RIP2-TRAF3-TBK1-IKK $\varepsilon$-IRF7 axis plays a key role in the induction of type I IFN responses via NOD1. ${ }^{10)}$ The interaction between RIP2 and TRAF3 appears to be a unique feature of NOD1 activation. It is reminiscent of the interaction between MyD88 and TRAF3, which plays an indispensable role in the generation of TLRs-induced type I IFN responses. ${ }^{72}$ )

Importantly, sensing of Gram-negative bacteria residing the GI tracts by intracellular NOD1 mediates mucosal host defense against gastric infection of H. pylori and development of pancreatitis through induction of type I IFN responses (see below). Moreover, recent studies by Fan et al. highlights the importance of NOD1-RIP2-mediated type I IFN responses in anti-viral host defense responses to cytomegalovirus infection of the GI tract. ${ }^{42)}$

The role of NOD1 in autophagy and in the endoplasmic reticulum stress response. NOD1 has a surprisingly important role in cellular homeostasis, one involving autophagy and the other, the unfolded protein response. Long-lived proteins and cytoplasmic organelles are degraded or are processed for recycling by a cellular mechanism known as autophagy. ${ }^{73)}$ During autophagy double-membrane vacuoles are formed that entrap targeted proteins and subject the latter to proteolytic digestion when the vacuoles are fused with lysosomes. Autophagy also provides machinery for the handling of bacteria that gain cellular entry, but the mechanism that links detection of such bacteria to autophagy is poorly understood. Insight into one such possible mechanism has been reported by Travassos et al. who found that invasive bacteria induce autophagic responses via binding of bacterial NOD1 ligand to cellular NOD1 at the bacterial entry site, which then triggers autophagy by NOD1 binding to ATG16L1, an autophagy-inducing protein. ${ }^{73), 74)}$ Such NOD1induced autophagy in epithelial cells was shown to control infection with invasive bacteria such as Shigella flexneri, but similar NOD1 interactions are presumably involved in the cellular entry of other bacteria as well.

The NOD1-mediated induction of autophagy described above is independent of NOD1 signaling involving RIP2. ${ }^{74}$ However, Irving et al. provided evidence that endosomal co-localization of NOD1 and RIP2 following bacterial OMV uptake leads to autophagy and inflammatory responses in gastric epithelial cells. ${ }^{17}$ ) Recently, data bearing on whether such RIP2-mediated autophagy depends on ATG16L1 was reported by Sorbara et al. ${ }^{75)}$ These authors found that epithelial cells subjected to ATG16L1-knockdown exhibit increased chemokine responses upon stimulation with NOD1 ligand. In addition, they found that such increased responses were dependent on RIP2 signaling since they were not seen in RIP2-deficient cells. ${ }^{75)}$ Conversely, epithelial cells over-expressing ATG16L1 exhibit markedly decreased K63-linked poly-ubiquitination of RIP2 upon activation of NOD1. These data thus suggest that interaction of NOD1 with ATG16L1 causes inhibition of RIP2 poly-ubiquitination and thus inhibition of NOD1-RIP2 pro-inflammatory signaling. Importantly, such negative regulation of NOD1-RIP2 signaling by ATG16L1 was independent of autophagic responses, implying that the NOD1 induction of autophagy via activation of RIP2 reported by Irving involves an autophagy-inducing mechanism independent of ATG16L1.

The accumulation of unfolded or misfolded proteins caused by endogenous cellular factors or microbial infection can trigger endoplasmic reticulum (ER) stress, a possible pro-inflammatory mechanism underlying Crohn's disease or type 2 diabetes. ER stress induces inflammation by initiating the unfolded protein response (UPR), a process that is marked by the activation of three ER transmembrane receptors: protein kinase RNA-like endoplasmic reticulum kinase (PERK), activating transcription factor 6 (ATF6) and inositol-requiring enzyme 1 (IRE1 $\alpha){ }^{76)}$ One of these ER receptors, IRE1 $\alpha$, accounts for the pro-inflammatory potential of the UPR by recruiting TRAF2 to the ER membrane and thus the activation of NF- $\kappa \mathrm{B}$ and the production of IL-6. ${ }^{76)}$ Unexpectedly, recent studies show that IRE1 $\alpha$ / TRAF2 interaction leading to the induction of NF$\kappa \mathrm{B}$ requires recruitment of NOD1-RIP2 or NOD2RIP2 and ligand-independent activation of the latter innate immune factors. ${ }^{77}$ ) Thus, atypical activation of NOD1 (and NOD2) plays important roles in the ER stress-induced inflammatory responses.

\section{NOD1 and Helicobacter pylori infection}

Activation of NOD1 by $\boldsymbol{H}$. pylori. Persistent gastric infection of $H$. pylori causes a wide variety of human upper GI tract disorders including chronic gastritis, peptic ulcers, mucosa-associated lymphoid 
tissue lymphoma, and gastric cancer. ${ }^{78)}$ H. pylori organisms are classified into two strains of differing pathogenicity conferred by the expression of cytotoxin-associated gene $\mathrm{A}(\mathrm{CagA})$, a virulence protein encoded by the $\operatorname{cag} A$ gene. The $\operatorname{cag} A$ gene is one of the 28-30 genes comprising the cag pathogenicity island that together provide the proteins necessary for the expression of a syringe needle-like structure known as the type IV section system (T4SS) that allows efficient $H$. pylori injection of toxins and bacterial cell wall components into gastric epithelial cells. ${ }^{78), 79)}$

Viala et al. provided the first evidence that intracellular NOD1 in gastric epithelial cells detects NOD1 ligand derived from $H$. pylori PGN and that such detection has host defense implications. ${ }^{9)}$ These authors showed first that such detection was CagAdependent since $H$. pylori expressing a functional T4SS but not a non-functional T4SS, activated NOD1 as assessed by reporter gene assays. They then showed that NOD1-deficient mice exhibit increased bacterial burdens of T4SS-bearing H. pylori organisms as compared with NOD1-intact mice upon acute infection with these organisms. ${ }^{9 \text { ) }}$

Whereas CagA injection of PGN into cells may be the primary mechanism of intra-cellular entry of NOD1 ligand as suggested by Viala et al., NOD1 ligand may also gain entry into the cell in a T4SSindependent fashion via H.pylori-derived OMVs. As indicated above, the latter are cell membrane structures released from cells and containing cell contents (such as H. pylori PGN) that can be transported across the cell membrane by lipid rafts. ${ }^{80)}$ This mechanism of PGN-NOD1 ligand entry has also been shown to have host defense implications in that it results in NOD1-dependent NF- $\kappa \mathrm{B}$ activation and pro-inflammatory chemokine responses. ${ }^{80)}$ Recently, Irving et al. elucidated the molecular mechanism accounting for NOD1-mediated detection of $H$. pylori-derived NOD1 ligand via OMV-transmembrane transport. ${ }^{17)}$ They reported that upon entry into the cell, OMVs derived from H. pylori induces autophagosome formation in a NOD1 and RIP2-dependent manner and that OMV and their contained PGN then co-localize with both NOD1 and RIP2 in early endosomes. ${ }^{17)}$ Thus, these results suggest that $H$. pylori-derived OMVs are internalized and digested into PGN fragments by formation of autophagosomes and that sensing of PGN by NOD1 is achieved in the early endosomes.

NOD1-mediated mucosal host defense against $H$. pylori (Figure 2 and Table 1). Host defense elicited by persistent gastric infection of
H. pylori is mediated, at least in part, by a strong Th1 immune response since it has been shown that such responses are necessary to obtain reductions in the gastric bacterial load ${ }^{81), 82)}$ and to correlate with vaccine-induced reductions of $H$. pylori colonization. ${ }^{83)}$ Whether these adaptive host defense responses are accompanied or enhanced by innate TLRs-induced immune responses, is uncertain since the stimulatory activity of TLR4 by lipopolysaccharide (LPS) isolated from $H$. pylori is much weaker than that from Escherichia coli or Salmonella typhimurium and H. pylori flagellin has little ability to stimulate TLR5 responses. ${ }^{84), 85)}$

On the other hand, studies by Viala et al. mentioned above have provided evidence that innate responses, in this case mediated by NOD1, do have a major role in host defense against $H$. pylori. This consists of the fact that NOD1-deficient mice are both susceptible to gastric infection with $H$. pylori and, in addition, exhibit increased gastric bacterial burden upon such infection. ${ }^{9), 10)}$ One question arising from this observation is if and how activation of an innate NOD1 response might generate an adaptive Th1 response against $H$. pylori. In studies addressing this question and already discussed above in the section of NOD1 signaling pathways, Watanabe et al. showed that stimulation of gastric epithelial cells by NOD1 ligand induces a robust production of IFN- $\beta$ and that such type I IFN production leads to a marked production of Th1 chemokines such as CXCL9, CXCL10, and CXCL11. ${ }^{10)}$ This suggested that NOD1 activation in gastric epithelial cells triggers adaptive Th1 responses against $H$. pylori via its capacity to induce type I IFN production. In vivo support of this conclusion came from studies showing that acute gastric infection of $H$. pylori upregulates expression of IFN- $\gamma, \mathrm{IFN}-\beta$, and CXCL10 in the gastric mucosa of NOD1-intact mice and that mice that are deficient in NOD1 or type I IFN receptor expression exhibit increased bacterial burden following oral challenge with $H$. pylori as compared with NOD1-intact or type I IFN receptorintact mice. ${ }^{10)}$

The role of epithelial cells in NOD1 induction of Th1 responses during H. pylori infection discussed above is highlighted by the fact that CXCL10 produced by such cells attracts CXCR3-expressing Th1 cells ${ }^{66)-68)}$ and that expression of CXCL10 is in fact observed in the stomach of patients with H. pylori infection. ${ }^{86)}$ Furthermore, since the major Th1 cytokine, IFN- $\gamma$, up-regulates NOD1 expression, ${ }^{10), 41)}$ adaptive Th1 cells producing IFN- $\gamma$ may 


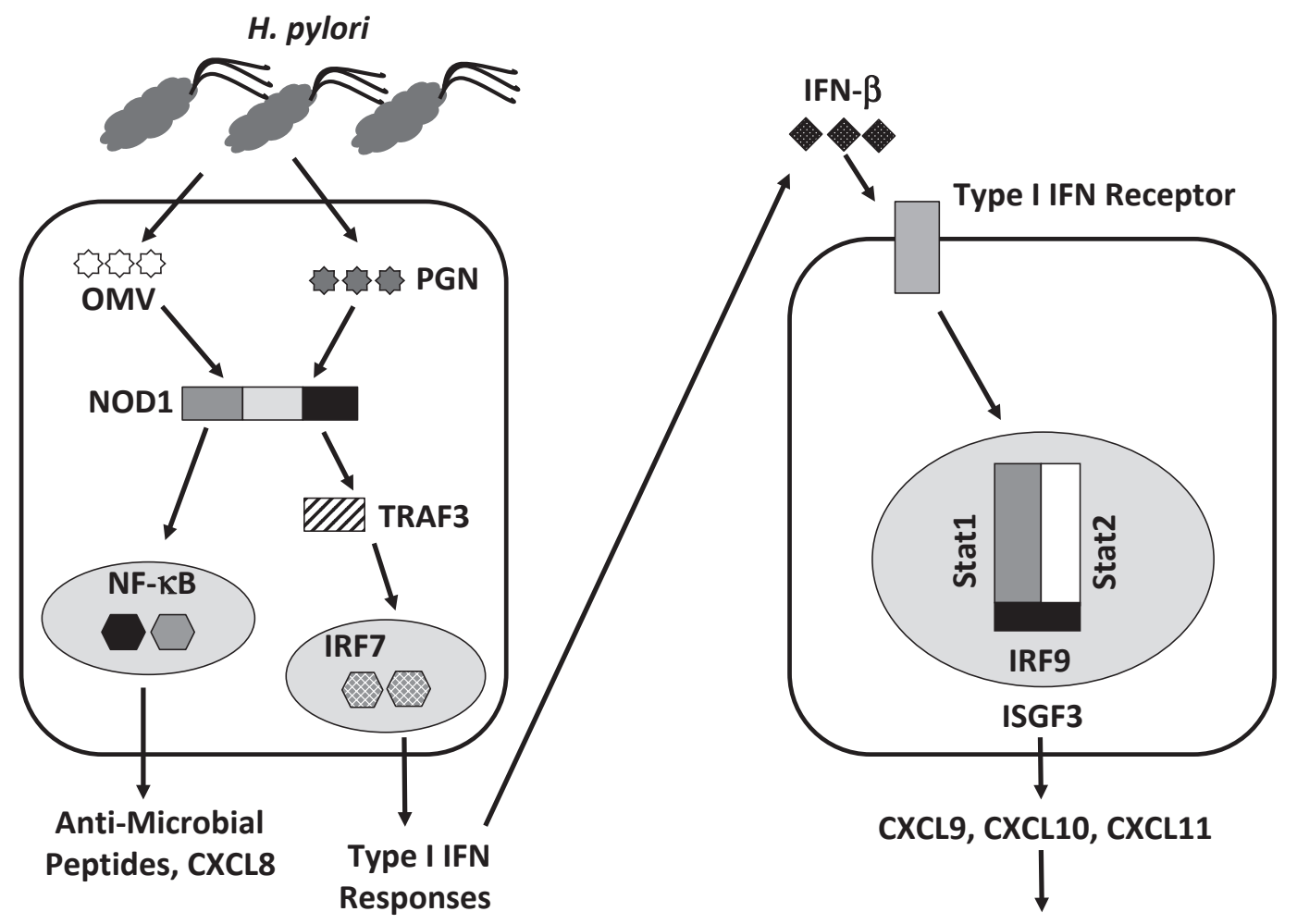

TH1 Responses

Fig. 2. Involvement of NOD1 in mucosal host defense against Helicobacter pylori infection. Nucleotide-binding oligomerization domain 1 (NOD1) expressed in gastric epithelial cells detects peptidoglycan (PGN) or outer membrane vesicles (OMVs) derived from Helicobacter pylori (H. pylori). Sensing of PGN or OMV by NOD1 causes nuclear translocation of nuclear factor- $\kappa \mathrm{B}$ (NF- $\kappa \mathrm{B})$ subunits to induce production of C-X-C motif chemokine ligand 8 (CXCL8) and anti-microbial peptides. Sensing of PGN by NOD1 causes nuclear translocation of interferon regulatory factor 7 (IRF7) through activation of TNF receptor associated factor 3 (TRAF3) to induce production of IFN- $\beta$. Production of IFN- $\beta$ causes activation of interferon stimulated gene factor 3 (ISGF3), a heterotrimer composed of signal transduction and activator of transcription 1 (Stat1), Stat2, and IRF9 to induce production of T helper type 1 (Th1) chemokines such as CXCL9, CXCL10, and CXCL11.

Table 1. NOD1 activation and gastrointestinal disorders

\begin{tabular}{|c|c|c|c|c|}
\hline & NOD1-trigerring factors & NOD1-expressing cells & $\begin{array}{l}\text { Responses induced by } \\
\text { NOD1 activation }\end{array}$ & Outcome \\
\hline $\begin{array}{l}\text { H. pylori-associated } \\
\text { gastritis }\end{array}$ & $\begin{array}{c}\text { Type IV secretion system, } \\
\text { OMV transport }\end{array}$ & Gastric epithelial cells & $\begin{array}{rc}\text { AMP } & \uparrow \\
\text { CXCL8 } & \uparrow \\
\text { CXCL10 } & \uparrow \\
\text { Type I IFN } & \uparrow\end{array}$ & $\begin{array}{c}\text { Protection against } \\
\text { infection }\end{array}$ \\
\hline $\begin{array}{l}\text { H. pylori-associated } \\
\text { gastric cancer }\end{array}$ & $\begin{array}{c}\text { Type IV secretion system, } \\
\text { OMV transport }\end{array}$ & Gastric epithelial cells & CDX2 & $\begin{array}{c}\text { Cancer development } \\
\text { inhibition }\end{array}$ \\
\hline Acute pancreatitis & Bacterial translocation & Pancreatic acinar cells & $\begin{array}{rc}\text { CCL2 } & \uparrow \\
\text { Type I IFN } & \uparrow\end{array}$ & $\begin{array}{c}\text { Induction of acute } \\
\text { pancreatitis }\end{array}$ \\
\hline Chronic pancreatitis & Bacterial translocation & Pancreatic acinar cells & $\begin{array}{rc}\text { Type I IFN } & \uparrow \\
\text { CCL2 } & \uparrow \\
\text { IL-33 } & \uparrow\end{array}$ & $\begin{array}{c}\text { Induction of chronic } \\
\text { pancreatitis }\end{array}$ \\
\hline
\end{tabular}


activate innate immune responses through their effect on epithelial expression of NOD1, correlating with the fact that significantly increased expression of NOD1, IFN- $\gamma$, and CXCL10 has been seen in human gastric biopsies displaying severe H. pylorirelated gastritis as compared with those displaying mild gastritis. ${ }^{87)}$ Taken together, these findings suggest the existence of a positive feedback loop between NOD1 responses of epithelial cells and Th1 responses of lymphoid cells.

As mentioned above, the RIP2-TRAF3-TBK1IKK $\varepsilon$-IRF7 axis leading to signaling via the type I IFN receptor and activation of ISGF3 plays a major role in NOD1 induction of type I IFN responses in gastric epithelial cells. ${ }^{10)}$ Thus, NOD1 activation of CXCL9, CXCL10, and CXCL11 transcription via type I IFN requires nuclear translocation of ISGF3, a complex composed of Stat1, Stat2, and IRF9. ${ }^{10)}$ On this basis Watanabe et al. examined the activation status of ISGF3 components in the gastric mucosa of mice challenged with $H$. pylori and found that Stat1 and Stat2 activation was enhanced in the gastric mucosa of NOD1-intact mice whereas no such activation was observed in NOD1-deficient mice. ${ }^{10)}$ Furthermore, NOD1-intact mice treated with Stat1specific siRNA exhibited increased bacterial burden of $H$. pylori in the stomach with diminished production of CXCL10 and IFN- $\gamma \cdot{ }^{10)}$ Thus, it was evident that NOD1 induction of type I IFN in epithelial cells does require activation of ISGF3.

Interestingly, although $\mathrm{NF}-\kappa \mathrm{B}$ activation is a major outcome of NOD1-mediated signaling, NOD1mediated mucosal host defense against acute infection with $H$. pylori does not depend on NF- $\kappa \mathrm{B}$ activation. This became apparent from the fact that treatment of $H$. pylori-challenged mice with NF- $\kappa \mathrm{B}$ decoy oligonucleotides did not reduce the gastric expression of Th1 chemokines as compared with mice treated with control scrambled oligonucleotides, although treatment with $\mathrm{NF}-\kappa \mathrm{B}$ decoy oligonucleotides did lead to a marked reduction in the expression of NF- $\kappa$ B-related genes such as TNF and CXCL2. ${ }^{10)}$ Thus, NOD1 mediates mucosal host defense against H. pylori through the type I IFN-ISGF3 pathway rather than the $\mathrm{NF}-\kappa \mathrm{B}$ pathway. In line with this conclusion, Hirata et al. showed that activation of $\mathrm{NF}-\kappa \mathrm{B}$ induced by infection with $H$. pylori does not depend upon NOD1. ${ }^{88)}$

Detection of $H$. pylori-derived PGN by NOD1 in gastric epithelial cells induces other anti-microbial responses in addition to those involving type I IFN described above. Thus, H. pylori infection of gastric epithelial cells causes IL-8 production via NOD1dependent MAPK activation and thereby leads to the migration of neutrophils into the gastric mucosa. ${ }^{89)}$ In addition, NOD1 causes epithelial cell release of AMPs capable of direct killing of $H$. pylori organisms. ${ }^{33)}$ It is therefore obvious that NOD1 utilizes various pathways to protect the hosts from gastric infection with $H$. pylori.

NOD1 activation and gastric cancer (Figure 3 and Table 1). Chronic infection of the gastric mucosa with $H$. pylori is the strongest known risk factor for the development of gastric carcinogenesis. ${ }^{78)}$ This is most likely related to the fact that chronic immune stimulation of the mucosal immune system creates a local milieu that supports malignant

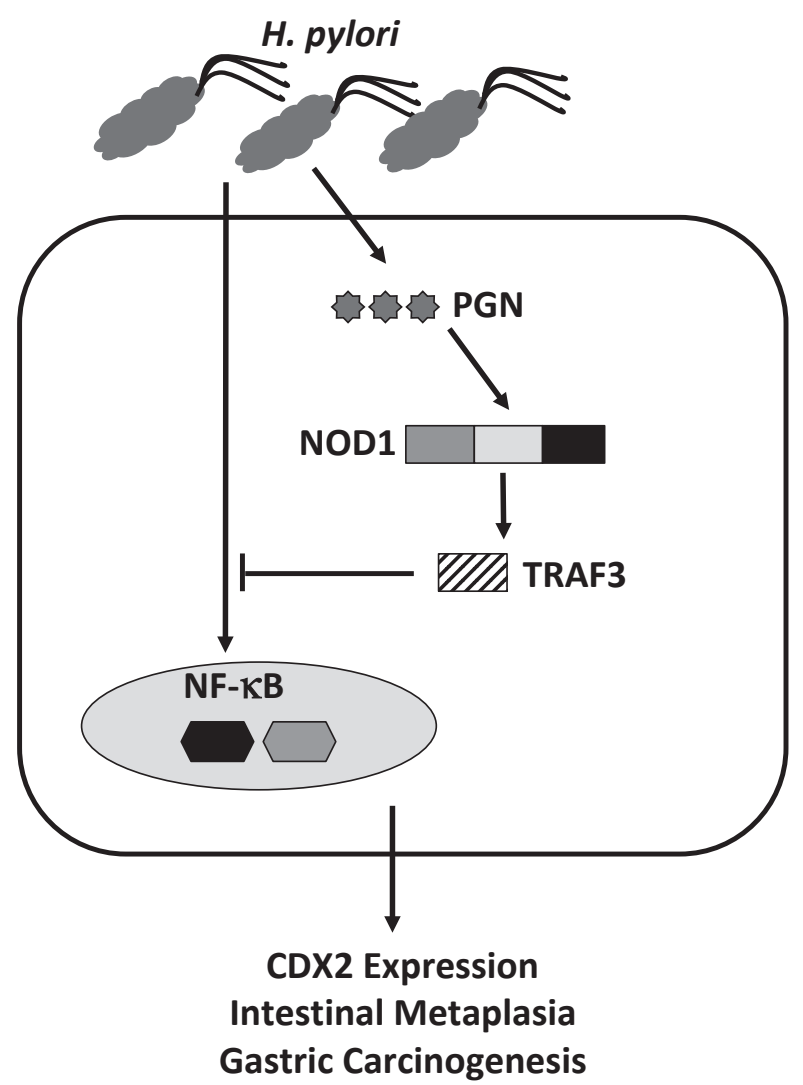

Fig. 3. Involvement of NOD1 in gastric carcinogenesis associated with Helicobacter pylori infection. Nucleotide-binding oligomerization domain 1 (NOD1) expressed in gastric epithelial cells detects peptidoglycan (PGN) derived from Helicobacter pylori (H. pylori). Exposure to H. pylori in gastric epithelial cells causes nuclear translocation of nuclear factor- $\kappa \mathrm{B}(\mathrm{NF}-\kappa \mathrm{B})$ subunits to induce expression of caudal-type homeobox protein 2 (CDX2), a critical factor for intestinal metaplasia and gastric carcinogenesis. This induction of CDX2 expression is negatively regulated by activation of NOD1-TNF receptor associated factor 3 (TRAF3) pathways 
transformation of epithelial cells such as the induction of cytokines that induce transformation of cells with up-regulated oncogenes; however, it is also possible that immune responses can protect against malignant transformation. As described above, NOD1 is a major innate immune sensor of $H$. pylori infection and is therefore likely to be involved in the development of $H$. pylori-associated gastric cancer, either as positive or negative factor. Indeed, Suarez et al. performed expression analysis of NOD1 in the human gastric cancer mucosa and non-cancer muco$\mathrm{sa}^{90)}$ and found that epithelial staining intensity of NOD1 was much lower in gastric cancer mucosa as compared with non-cancer mucosa, suggesting that that in this case, an innate immune response is serving to protect against the development of gastric cancer. ${ }^{90)}$

Caudal-type homeobox protein $2(\mathrm{Cdx} 2)$ is a gastric epithelial cell-derived trans-differentiation factor that plays a pivotal but as yet poorly understood role in the development of "intestinal type" gastric adenocarcinoma; as such its expression serves as a harbinger of eventual development of gastric malignancy. ${ }^{91)}$ Thus, as expected, expression of Cdx2 was significantly higher in human gastric cancer mucosa than in non-cancerous mucosa. Asano et al., explored the possibility that NOD1 was affecting malignant transformation via an effect on $\mathrm{Cdx} 2$ expression and conducted extensive studies elucidating the molecular mechanisms governing the relation of NOD1 signaling and Cdx2 expression. ${ }^{11)}$ They found that $\mathrm{Cdx} 2$ expression in epithelial cell lines is induced by infection with $H$. pylori and that such expression is dependent on NF- $\kappa \mathrm{B}$ activation. Unexpectedly, they also found that activation of NOD1 negatively regulates $H$. pylori-induced $\mathrm{Cdx} 2$ expression since siRNA-mediated knockdown of NOD1 markedly enhanced $\mathrm{Cdx} 2$ expression upon exposure to H. pylori. In line with previous findings discussed above showing that NOD1/RIP2-mediated TRAF3 activation triggers type I IFN responses rather than NF$\kappa$ B-related responses, ${ }^{10)} \mathrm{Cdx} 2$ expression induced by exposure to $H$. pylori was markedly reduced in gastric cancer cells overexpressing TRAF3. They thus concluded that the unique ability of NOD1-activated RIP2 to interact with TRAF3 leads to downregulation of $\mathrm{NF}-\kappa \mathrm{B}$ support of $\mathrm{Cdx} 2$ expression.

In related studies, Asano et al. provide in vivo data that support the in vitro findings described above. ${ }^{11)}$ First, they found that the frequency of goblet cells, highly indicative of pre-cancerous intestinal metaplasia, was more evident in the gastric mucosa of NOD1-deficient mice 12 months after infection with $H$. pylori than in NOD1-intact mice. Moreover, gastric tissues of NOD1-deficient mice with prolonged $H$. pylori infection exhibited higher levels of $\mathrm{Cdx} 2$ expression and lower levels of TRAF3 expression than those of NOD1-intact mice. Moreover, nuclear translocation of NF- $\kappa \mathrm{B}$ subunit p65 was enhanced in the gastric tissues of NOD1-deficient mice with prolonged $H$. pylori infection as compared with those of NOD1-intact mice. These in vivo studies thus again suggest that NOD1 activation of TRAF3 and the latter's inhibition of NF- $\kappa \mathrm{B}$ activation suppress gastric carcinogenesis induced by prolonged $H$. pylori infection. It should be noted that this conclusion meshes quite well with the role of NOD1 as a host defense factor in protection against H. pylori infection since in both cases NOD1 is operating via a TRAF3-mediated signaling pathway that favors type I IFN responses rather than NF- $\kappa \mathrm{B}$ responses.

\section{NOD1 and pancreatitis}

Trypsinogen activation and pancreatitis. Pancreatitis is one of the major inflammatory disorders of the GI tract and as such has been subjected to considerable research probing its pathogenesis. ${ }^{92), 93)}$ Nevertheless, it remains poorly understood, particularly with respect to the possible contribution of causative immunologic factors. Recently, it has been discovered that NOD1 plays a major pathogenic role in pancreatitis and will be the focus of this analysis of pancreatitis pathogenesis. ${ }^{14)}$

It is useful to discuss the acute and chronic forms of pancreatitis separately because, while these types of pancreatitis share underlying features, they also have specific manifestations. Acute pancreatitis is defined as sudden inflammation of the exocrine pancreas occurring in a previously normal pancreas and that may undergo resolution without causing permanent pancreatic damage. Chronic pancreatitis is a persistent inflammation of the pancreas usually punctuated by acute exacerbations and occurring in a pancreas that bears the marks of previous episodes of inflammation. ${ }^{14), 94), 95)}$

An underlying feature of both acute and chronic pancreatitis is dysfunction in the management of potentially corrosive digestive enzymes that are secreted by the pancreas into the intestine and are necessary for normal digestion. In the normal state these enzymes are synthesized in pancreatic acinar cells as inactive pro-enzymes (such as trypsinogen) and are maintained in this state until activated by 
enterokinase upon entry into the gut lumen. ${ }^{96), 97)}$ It is widely believed that pancreatitis is initiated by genetic or environmental factors (the latter including excessive alcohol intake or intake of high fat foods) that cause inappropriate intra-pancreatic activation of pancreatic digestive enzymes, especially trypsinogen, and this is followed by auto-digestion of pancreatic tissue and inflammation. ${ }^{96), 97)}$

Strong support of this "trypsin-centered" theory of pancreatitis pathogenesis comes from studies of hereditary pancreatitis in humans. ${ }^{98)}$ In these studies it was found that various pancreatitis-associated mutations of PRSS1 gene (the gene encoding the main form of trypsinogen, cationic trypsinogen) lead to a form of trypsinogen that is subject to inappropriate activation or to resistance to intra-cellular degradation after inadvertently activation. ${ }^{98)}$ In addition, various mutations of the pancreatitisassociated gene, serine protease inhibitor, Kazal type I (SPINK1) gene (the gene encoding an inhibitor of activated trypsin) impairs negative regulation of trypsinogen activation occurring in acinar cells. ${ }^{98)}$ Thus, these genetic studies as well as studies of experimental pancreatitis in mice ${ }^{14), 98)}$ bolster the concept that inappropriate trypsinogen activation followed by auto-digestion initiates and sustains inflammatory responses of the pancreas.

The trypsin-centered theory of pancreatitis has recently been challenged by an extensive analysis of T7 trypsinogen-depleted mice, i.e., mice that do not synthesize the murine form of trypsin thought to be equivalent to human inflammation-inducing cationic trypsin mentioned above. ${ }^{99)-101)}$ Mice deficient in T7 trypsinogen exhibit a marked reduction in activation of trypsinogen but nevertheless exhibit comparable levels of acute and chronic experimental pancreatitis induced by repeated injections of cerulein, a cholecystokinin receptor (CCKR) agonist as observed in wild type mice. ${ }^{99), 100)}$ These results thus suggested that experimental pancreatitis can occur independently of trypsinogen activation and that pathogenesis of pancreatitis cannot be explained by the trypsincentered theory alone. It should be noted, however, that these studies do not rule out the possibility that in vivo, potentially inflammatory trypsinogen may not consist of $\mathrm{T} 7$ trypsinogen alone and that $\mathrm{T} 7$ trypsinogen depletion leaves intact other isoforms of trypsinogen that could still be mediating pancreatitis. On this basis, the most reasonable interpretation of studies on the role of trypsinogen activation as an initiator and sustainer of pancreatitis is that such activation is necessary but not sufficient as a cause of pancreatitis and that other presumably immunerelated causes must be operative as well.

NOD1 activation and acute pancreatitis (Figure 4 and Table 1). Although in most patients acute pancreatitis is a self-limited inflammation in some patients a severe form of acute pancreatitis occurs that be associated with systemic manifestations of infection. ${ }^{95)}$ Ultimately it was found that this clinical outcome was the result of bacterial colonization of the inflamed pancreas followed by infection of necrotic pancreatic tissue. ${ }^{95)}$ Thus, such cases provided initial clinical evidence that pancreatitis is associated with disruption of the intestinal barrier followed by entry of intestinal microflora into the circulation and colonization of the pancreas. ${ }^{12), 102)-107)}$ This was more definitively examined in studies of experimental pancreatitis wherein it was formally shown that mice with pancreatitis have increased bowel permeability and that particles with the size of bacteria have been translocated into the pancreas. ${ }^{102-107)}$ Studies in humans of the types of organisms that enter the circulation by Li et al. using 16S rRNA based technology revealed that a broad range of bacteria are detected in the circulation of about $70 \%$ of patients; these bacteria were similar to commensal organisms in the GI tract and the latter were presumed to be their origin; however, in some cases the organisms were pathogens, perhaps accounting for the more severe cases of pancreatitis mentioned above. ${ }^{108)}$ Of interest, bowel sterilization with a broad range of antibiotics effectively prevented the development of experimental pancreatitis; this finding suggested that translocated organisms play a significant role in pancreatitis pathogenesis. ${ }^{12), 105)-107)}$

In initial studies designed to clarify the immune responses against intestinal microflora that might be playing a role in acute pancreatitis Watanabe and his colleagues subjected mice deficient in various innate immune receptors to experimental pancreatitis induced by repeated administration of relatively high doses of cerulein $(50 \mu \mathrm{g} / \mathrm{kg})$, the latter an agent that causes pancreatitis via excessive stimulation of the CCKR. ${ }^{12)}$ They found that TLR2 and TLR9 deficient mice exhibited levels of pancreatitis equivalent to that in wild type mice and that TLR4-deficient mice, (that cannot respond to LPS) exhibited somewhat less pancreatitis than wild type mice. However, quite surprisingly, mice deficient in NOD1 were completely resistant to the development of cerulein-induced pancreatitis, indicating that innate recognition of NOD1 ligand derived from gut bacteria plays a major role in the development of pancreatitis. A central 


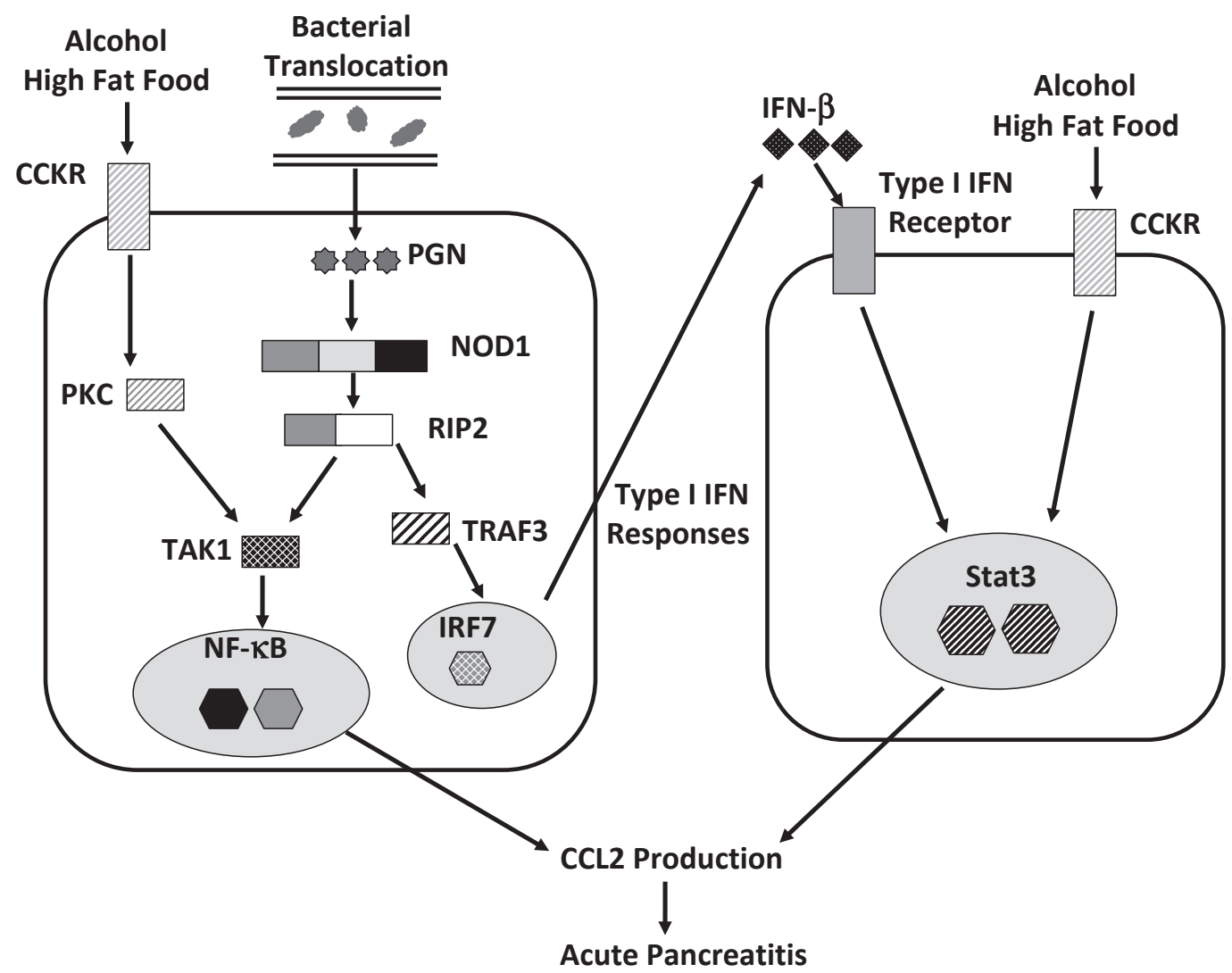

Fig. 4. Involvement of NOD1 in acute pancreatitis. Excessive drinking of alcohol and intake of high fat foods cause cholecystokinin receptor (CCKR) signaling pathways to induce intra-acinar activation of trypsinogen. Nucleotide-binding oligomerization domain 1 (NOD1) expressed in pancreatic acinar cells detects peptidoglycan (PGN) derived from intestinal microflora translocated into the pancreas. CCKR-mediated signaling pathway causes nuclear translocation of nuclear factor- $\kappa \mathrm{B}(\mathrm{NF}-\kappa \mathrm{B})$ subunits through the interaction between protein kinase $\mathrm{C}$ (PKC) and TGF- $\beta$-activated kinase 1 (TAK1). NOD1-mediated signaling pathway causes nuclear translocation of NF- $\kappa \mathrm{B}$ subunits through the interaction between receptor interacting protein 2 (RIP2) and TAK1. Synergistic activation of NF- $\kappa$ B is achieved by simultaneous activation of CCKR and NOD1. Sensing of PGN by NOD1 causes nuclear translocation of interferon regulatory factor 7 (IRF7) through activation of TNF receptor associated factor 3 (TRAF3) to induce production of IFN- $\beta$. Production of IFN- $\beta$ induced by NOD1 activation acts together with CCKR activation to induce optimal activation of signal transduction and activator of transcription 3 (Stat3). Simultaneous activation of NOD1 and CCKR leads to a robust production of C-C motif chemokine ligand 2 (CCL2) by pancreatic acinar cells through activation of NF- $\kappa$ B and Stat3, which mediates migration of inflammatory myeloid cells into the pancreas.

question raised by this observation as well as the relation of pancreatitis to bacterial translocation discussed above, is why gut bacteria enter the circulation during acute pancreatitis. The most likely answer to this question is that pancreatic inflammation initially arising from trypsin activation sets in motion the intra-pancreatic activation of innate immune receptors that recognize damage-associated molecular patterns (DAMPs) released from dying pancreatic cells and then stimulate the production of a set of cytokines that change gut permeability and mediate bacterial translocation. ${ }^{109)-111)}$

To further define the role of NOD1 in the development of acute pancreatitis, Watanabe et al., established a new model of acute pancreatitis induced by simultaneous and repeated administration of low doses of cerulein $(20 \mu \mathrm{gg} / \mathrm{kg})$ and FK156, an activator of NOD1 that mimics the effect of gut bacteria that have breached the mucosal barrier. The value of this method of inducing pancreatitis resided in the fact that whereas administration of low doses of cerulein alone or NOD1 ligand alone did not induce pancreatitis, the simultaneous administration of these agents does induce pancreatitis; thus this model enables one to analyze the separate molecular mechanisms of inflammation induced by each of the agents causing pancreatitis. $^{12)}$ 
In initial studies utilizing this model, Watanabe et al. conducted bone marrow transplantation studies to determine the type of cells expressing NOD1 in the development of pancreatitis. ${ }^{12)}$ They found that one could successfully induce acute pancreatitis in X-irradiated NOD1-intact mice transplanted with NOD1-deficient hematopoietic cells, but not in Xirradiated NOD1-deficient mice transplanted with NOD1-intact hematopoietic cells. ${ }^{12}$ ) These results strongly suggest NOD1 must be expressed in nonhematopoietic cells, most likely pancreatic acinar cells, to support pancreatitis development.

In related studies they determined the chemokines responsible for development of pancreatitis in this new model of pancreatitis. Here they found that simultaneous activation of NOD1 and cerulein stimulation of the CCKR led to robust production of C-C motif chemokine ligand 2 (CCL2) by pancreatic acinar cells and that mice deficient in $\mathrm{C}-\mathrm{C}$ chemokine receptor type 2 (CCR2) did not develop pancreatitis. ${ }^{12)}$ Thus, CCL2 produced by pancreatic acinar cells emerged as the key pathogenic chemokine in the development of acute pancreatitis induced by simultaneous activation of NOD1 and CCKR.

Finally, Watanabe et al. took advantage of the low dose cerulein-NOD1 ligand model of experimental acute pancreatitis described above to analyze the separate and synergistic acinar cell signaling induced by simultaneous NOD1 ligand and low dose cerulein stimulation characterizing the induction of pancreatitis. First, they found that both CCKR stimulation by cerulein and NOD1 signaling by NOD1 ligand was necessary for the activation of $\mathrm{NF}-\kappa \mathrm{B}$, the single most important factor in the downstream pathway of pancreatic inflammation. Thus, whereas stimulation of CCKR by low dose cerulein induces protein kinase $\mathrm{C}$ (PKC) and TAK1 activation as in previous studies, ${ }^{112}$ ) the level of such activation by low dose cerulein alone is not sufficient to induce activation of $\mathrm{NF}-\kappa \mathrm{B}$; likewise, NOD1 activation of RIP2 also is not sufficient to induce activation of NF- $\kappa \mathrm{B}$. In contrast, simultaneous activation of these pathways by NOD1 ligand and low dose cerulein administered together led to a level of TAK1 activation that was now sufficient to induce activation of NF- $\kappa$ B. This finding is seemingly at odds with the observation alluded to above that high dose cerulein administration is able to induce pancreatitis in the apparent absence of NOD1 ligand. However, this latter observation is more apparent than real, since high dose cerulein is able to induce a sufficient level of inflammation in the pancreas (via trypsin activation?) to cause translocation of gut bacteria into the circulation and thus stimulation of acinar cells by bacterial NOD1; thus even high dose cerulein requires NOD1 activation, as confirmed by the observation already discussed that high dose cerulein does not induce pancreatitis in the sterilized mouse.

A second set of insights derived from the low dose cerulein-NOD1 ligand pancreatitis model was that synergistic stimulation by NOD1 ligand and cerulein is also necessary for the optimal generation of Stat3, a signaling component necessary for the upregulation of CCL2 expression, the critically important chemokine necessary for the pancreatic influx of inflammatory macrophages. As noted in previous studies, stimulation of CCKR by cerulein results in the induction of Stat3 activation. ${ }^{113)}$ However, such induction is greatly enhanced by type I IFN induced by NOD1 signaling and thus simultaneous activation of NOD1 and CCKR induces synergistic and optimal, activation of Stat3 in pancreatic acinar cells. In addition, in line with the fact that the expression of CCL2 requires transactivation of $\mathrm{NF}-\kappa \mathrm{B}$ and Stat $3,{ }^{114)}$ synergistic activation of $\mathrm{NF}-\kappa \mathrm{B}$ and Stat3 induced by simultaneous injections with low doses of cerulein and NOD1 ligand is responsible for a robust production of CCL2 by pancreatic acinar cells.

Taken together, the model of experimental acute pancreatitis induced by low dose cerulein and NOD1 ligand provides a rich trove of new insights into the immuno-pathogenesis of pancreatitis that is likely to apply to human pancreatitis. Perhaps the most important of these is the increased recognition that bacteria entering the circulation as a result of DAMPs release in the pancreas and then stimulation of acinar cells via NOD1 are an essential feature of acute pancreatitis pathogenesis.

NOD1 activation and chronic pancreatitis (Figure 5 and Table 1). The model of acute pancreatitis described above to investigate the immunologic factors in the pathogenesis of pancreatitis was subsequently used as template by Watanabe et al., as a way to develop a model of chronic pancreatitis. In this chronic model, mice were again administered repeated doses of NOD1 ligand and low doses of cerulein, but in this case this regimen was maintained for a longer period of time. The chronic pancreatitis that ensued was characterized by a massive infiltration of immune cells and the appearance of a characteristic feature of chronic pancreatitis, intense fibrosis and reduction in functional pancreatic parenchymal mass. ${ }^{13)}$ As in the acute pancreatitis model, NOD1 expressed in pancreatic 


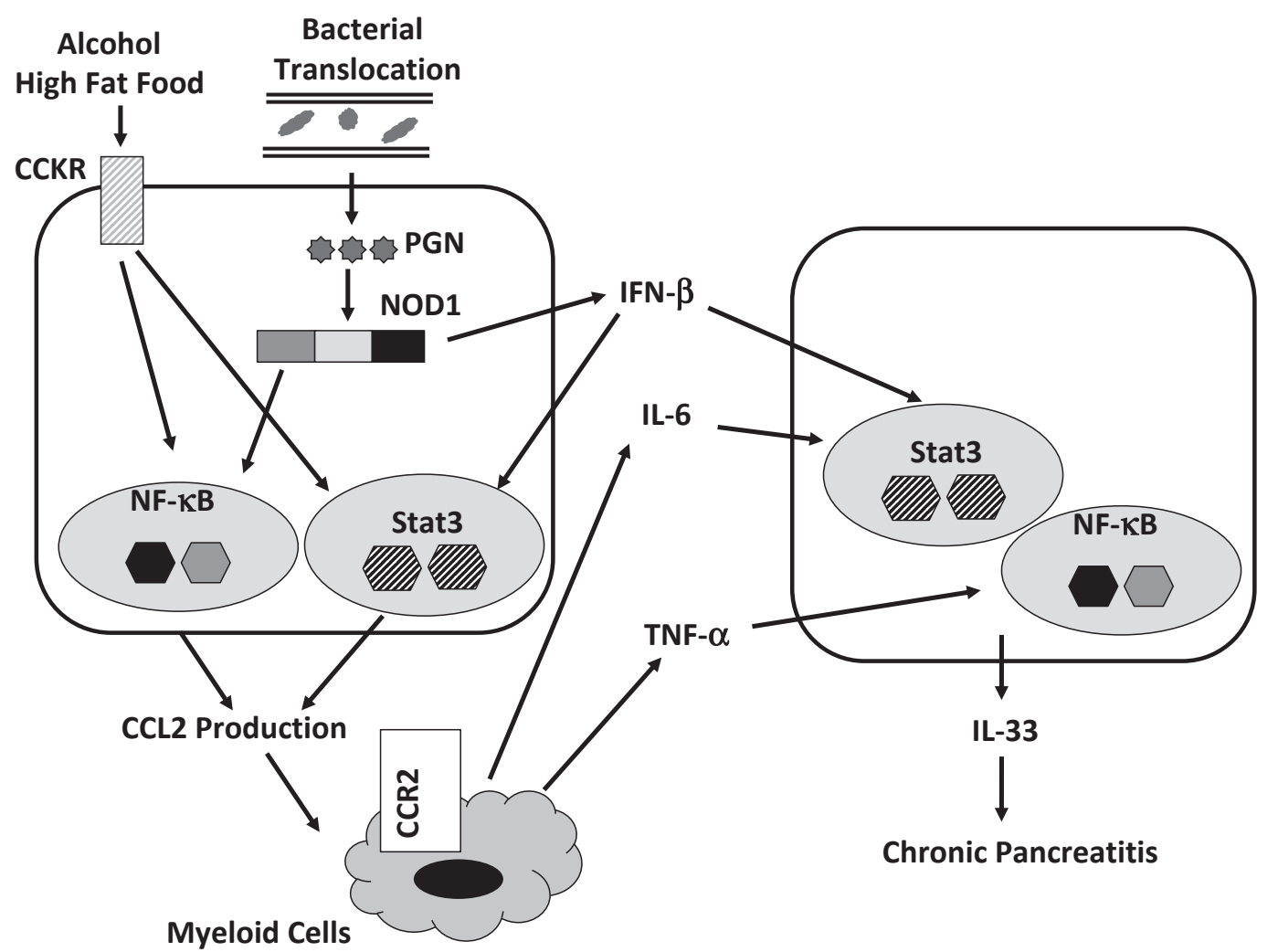

Fig. 5. Involvement of NOD1 in chronic pancreatitis. Simultaneous activation of nucleotide-binding oligimerization domain 1 (NOD1) and cholecystokinin receptor (CCKR) leads to a robust production of C-C motif chemokine ligand 2 (CCL2) through activation of nuclear factor- $\kappa \mathrm{B}(\mathrm{NF}-\kappa \mathrm{B})$ and signal transduction and activator of transcription 3 (Stat3), which mediates migration of C-C chemokine receptor type 2 (CCR2)-expressing inflammatory myeloid cells into the pancreas. CCR2-expressing inflammatory myeloid cells produce pro-inflammatory cytokines such as TNF- $\alpha$ and IL-6. TNF- $\alpha$ and IFN- $\beta$ produced by myeloid cells and pancreatic acinar cells, respectively, lead to a robust production of IL-33. IL-33 mediates chronic fibro-inflammatory responses of the pancreas.

acinar cells played an indispensable role in the chronic pancreatitis model as shown in studies of chimeric mice: X-irradiated NOD1-intact mice transplanted with NOD1-deficient hematopoietic cells were susceptible to chronic pancreatitis whereas Xirradiated NOD1-deficient mice transplanted with NOD1-intact hematopoietic cells were resistant to chronic pancreatitis. In addition, type I IFN responses were, as in the acute model, again shown to be essential for the development of pancreatitis as shown by the fact that type I IFN receptor-deficient mice were resistant to the development of chronic pancreatitis. The role of type I IFN in the induction of chronic pancreatitis is related to its capacity to elicit Stat3 activation and CCL2 expression necessary for the influx of the inflammatory macrophages that mediate the pancreatic inflammation (as briefly alluded to above in the discussion of acute pancreatitis). In addition, studies of the chronic model disclosed that type I IFN plays a key role in the macrophage TNF- $\alpha$ production, the cytokine most responsible for acinar cell death. Thus, in these studies it was shown that pancreatic acinar cells derived from the inflamed pancreas and co-cultured with $\mathrm{CD} 11 \mathrm{~b}^{+}$macrophages release increased amounts of IL-33. ${ }^{13), 14)}$ Moreover, it was shown that such IL33 secretion was inhibited by type I IFN receptor $\mathrm{Ab}$ or anti-TNF- $\alpha \mathrm{Ab}$, agents that block macrophage TNF- $\alpha$ production and acinar cell IL-33 production, respectively. ${ }^{13), 14)}$

In further studies of the chronic pancreatitis model, pancreatic lysates obtained from inflamed pancreas were analyzed to characterize the cytokine and chemokine responses accompanying the chronic pancreatic inflammation. As expected, these studies disclosed that a number of prototypical pro-inflammatory factors are produced in the chronic pancreatic tissue including TNF- $\alpha$, IL- 6 , IFN- $\gamma$, and IFN- $\beta$ among the cytokines and CCL2, CXCL9 and CXCL10 among the chemokines. In addition, the 
chronic pancreatitis was accompanied by secretion of several pro-fibrogenic cytokines such as IL-33, IL-13, and TGF- $\beta 1 .{ }^{115)-117)}$ Thus, chronic and simultaneous activation of NOD1 and CCKR enhances production of cytokines and chemokines that mediate both proinflammatory and pro-fibrogenic responses. ${ }^{13), 14)}$

Given the importance of pancreatic fibrosis in shaping the character of chronic pancreatitis, the chronic model was also used to define the mechanisms of fibrosis development in chronic pancreatitis. Perhaps the most important finding here was the fact that neutralization of IL-33 signaling by blockade of the IL-33 receptor with anti-ST2 Ab inhibited both inflammatory and fibrogenic responses due to accompanying reduction in the IL33-induced expression of TNF- $\alpha$, CCL2, IL-13, and TGF- $\beta 1$. As noted above, IL-33 production by acinar cells is increased upon coculture with pancreatic myeloid cells (macrophages) that are being stimulated by type I IFN, strongly suggesting that such myeloid cells produce TNF- $\alpha$ that induces IL-33 production by acinar cells. ${ }^{118)}$ Thus, the fibrosis of chronic pancreatitis has its origin in the inflammatory effect of macrophages on acinar cells. Finally, it is important to emphasize that IL-33 induction of fibrosis is directly correlated with its induction of IL-13, a cytokine that plays a critical role in tissue fibrogenesis generally ${ }^{115), 116)}$ as well as in the chronic pancreatitis model studied. The latter was established by studies showing that neutralization of IL-13 (by administration of anti-IL-13 Ab) protected mice from the development of fibrosis and that such neutralization was accompanied by reduced pancreatic expression of TGF- $\beta 1$, a major effector of fibrosis but not CCL2 and IFN- $\beta$, major pro-inflammatory factors. ${ }^{13)}$ Interestingly, the IL-13 induced by IL-33 was produced by $\mathrm{CD}^{+} \mathrm{T}$ cells inasmuch as $\mathrm{T}$ cell-deficient mice are resistant to the development of chronic pancreatitis. ${ }^{13)}$

\section{Concluding remarks}

This review of NOD1 function discloses that this NLR-type innate intra-cellular sensor of PGN peptides mediates a wide array of immunologic functions affecting host defense including activation of the $\mathrm{NF}-\kappa \mathrm{B}$ and MAPK responses as well as induction of the type I IFN response. As such, NOD1 plays a surprisingly important role in several inflammatory diseases of the GI tract including H. pylori infection of the gastric mucosa and in both acute and chronic pancreatitis. Thus, in H. pylori infection NOD1 is essential in the induction of protective type I IFN responses and activation of the ISGF3 signaling pathway. In addition, NOD1 inhibits gastric carcinogenesis through negative regulation of $\mathrm{Cdx} 2$ expression. Finally, in pancreatitis responses to translocated bacteria by NOD1 expressed by acinar cells are responsible both for the influx of inflammatory macrophages and for the acinar cell-destructive effect of TNF- $\alpha$ leading to the expression of IL-33 and pancreatic fibrosis. These newly defined roles of NOD1 in GI inflammation call attention to the possibility that manipulation of NOD1 function can be the focus of new forms of therapy.

\section{Acknowledgements}

This work was supported by Grants-in-Aid for Scientific Research $(25293172,15 \mathrm{~K} 15370)$ from the Japan Society for the Promotion of Science, the Kato Memorial Trust for Nambyo Research, the Naito Foundation, Yakult Bioscience Foundation, SENSHIN Medical Research Foundation, Smoking Research Foundation and Japan Agency for Medical Research and Development (AMED) Grants for Research on Intractable Diseases.

\section{References}

1) Akira, S. and Takeda, K. (2004) Toll-like receptor signalling. Nat. Rev. Immunol. 4, 499-511.

2) Pisetsky, D.S. (2008) The role of innate immunity in the induction of autoimmunity. Autoimmun. Rev. 8, 69-72.

3) Strober, W., Murray, P.J., Kitani, A. and Watanabe, T. (2006) Signalling pathways and molecular interactions of NOD1 and NOD2. Nat. Rev. Immunol. 6, 9-20.

4) Franchi, L., Warner, N., Viani, K. and Nunez, G. (2009) Function of Nod-like receptors in microbial recognition and host defense. Immunol. Rev. 227, 106-128.

5) Philpott, D.J., Sorbara, M.T., Robertson, S.J., Croitoru, K. and Girardin, S.E. (2014) NOD proteins: regulators of inflammation in health and disease. Nat. Rev. Immunol. 14, 9-23.

6) Caruso, R., Warner, N., Inohara, N. and Nunez, G. (2014) NOD1 and NOD2: signaling, host defense, and inflammatory disease. Immunity 41, 898-908.

7) Chamaillard, M., Hashimoto, M., Horie, Y., Masumoto, J., Qiu, S., Saab, L., Ogura, Y., Kawasaki, A., Fukase, K., Kusumoto, S., Valvano, M.A., Foster, S.J., Mak, T.W., Nunez, G. and Inohara, N. (2003) An essential role for NOD1 in host recognition of bacterial peptidoglycan containing diaminopimelic acid. Nat. Immunol. 4, 702-707.

8) Bouskra, D., Brezillon, C., Berard, M., Werts, C., Varona, R., Boneca, I.G. and Eberl, G. (2008) Lymphoid tissue genesis induced by commensals through NOD1 regulates intestinal homeostasis. Nature 456, 507-510. 
9) Viala, J., Chaput, C., Boneca, I.G., Cardona, A., Girardin, S.E., Moran, A.P., Athman, R., Memet, S., Huerre, M.R., Coyle, A.J., DiStefano, P.S., Sansonetti, P.J., Labigne, A., Bertin, J., Philpott, D.J. and Ferrero, R.L. (2004) Nod1 responds to peptidoglycan delivered by the Helicobacter pylori cag pathogenicity island. Nat. Immunol. 5, 11661174 .

10) Watanabe, T., Asano, N., Fichtner-Feigl, S., Gorelick, P.L., Tsuji, Y., Matsumoto, Y., Chiba, T., Fuss, I.J., Kitani, A. and Strober, W. (2010) NOD1 contributes to mouse host defense against Helicobacter pylori via induction of type I IFN and activation of the ISGF3 signaling pathway. J. Clin. Invest. 120, 1645-1662.

11) Asano, N., Imatani, A., Watanabe, T., Fushiya, J., Kondo, Y., Jin, X., Ara, N., Uno, K., Iijima, K., Koike, T., Strober, W. and Shimosegawa, T. (2016) Cdx2 expression and intestinal metaplasia induced by H. pylori infection of gastric cells is regulated by NOD1-mediated innate immune responses. Cancer Res. 76, 1135-1145.

12) Tsuji, Y., Watanabe, T., Kudo, M., Arai, H., Strober, W. and Chiba, T. (2012) Sensing of commensal organisms by the intracellular sensor NOD1 mediates experimental pancreatitis. Immunity 37, 326-338.

13) Watanabe, T., Sadakane, Y., Yagama, N., Sakurai, T., Ezoe, H., Kudo, M., Chiba, T. and Strober, W. (2016) Nucleotide-binding oligomerization domain 1 acts in concert with the cholecystokinin receptor agonist, cerulein, to induce IL-33-dependent chronic pancreatitis. Mucosal Immunol. 9, 1234-1249.

14) Watanabe, T., Kudo, M. and Strober, W. (2017) Immunopathogenesis of pancreatitis. Mucosal Immunol. 10, 283-298.

15) Sasawatari, S., Okamura, T., Kasumi, E., TanakaFuruyama, K., Yanobu-Takanashi, R., Shirasawa, S., Kato, N. and Toyama-Sorimachi, N. (2011) The solute carrier family 15A4 regulates TLR9 and NOD1 functions in the innate immune system and promotes colitis in mice. Gastroenterology 140, 1513-1525.

16) Nakamura, N., Lill, J.R., Phung, Q., Jiang, Z., Bakalarski, C., de Maziere, A., Klumperman, J., Schlatter, M., Delamarre, L. and Mellman, I. (2014) Endosomes are specialized platforms for bacterial sensing and NOD2 signalling. Nature 509, 240-244.

17) Irving, A.T., Mimuro, H., Kufer, T.A., Lo, C., Wheeler, R., Turner, L.J., Thomas, B.J., Malosse, C., Gantier, M.P., Casillas, L.N., Votta, B.J., Bertin, J., Boneca, I.G., Sasakawa, C., Philpott, D.J., Ferrero, R.L. and Kaparakis-Liaskos, M. (2014) The immune receptor NOD1 and kinase RIP2 interact with bacterial peptidoglycan on early endosomes to promote autophagy and inflammatory signaling. Cell Host Microbe 15, 623-635.

18) Fritz, J.H., Girardin, S.E., Fitting, C., Werts, C., Mengin-Lecreulx, D., Caroff, M., Cavaillon, J.M.,
Philpott, D.J. and Adib-Conquy, M. (2005) Synergistic stimulation of human monocytes and dendritic cells by toll-like receptor 4 and NOD1and NOD2-activating agonists. Eur. J. Immunol. 35, 2459-2470.

19) Tada, H., Aiba, S., Shibata, K., Ohteki, T. and Takada, H. (2005) Synergistic effect of Nod1 and Nod2 agonists with toll-like receptor agonists on human dendritic cells to generate interleukin-12 and $\mathrm{T}$ helper type 1 cells. Infect. Immun. 73, 7967-7976.

20) Fritz, J.H., Le Bourhis, L., Sellge, G., Magalhaes, J.G., Fsihi, H., Kufer, T.A., Collins, C., Viala, J., Ferrero, R.L., Girardin, S.E. and Philpott, D.J. (2007) Nod1-mediated innate immune recognition of peptidoglycan contributes to the onset of adaptive immunity. Immunity 26, 445-459.

21) Magalhaes, J.G., Rubino, S.J., Travassos, L.H., Le Bourhis, L., Duan, W., Sellge, G., Geddes, K., Reardon, C., Lechmann, M., Carneiro, L.A., Selvanantham, T., Fritz, J.H., Taylor, B.C., Artis, D., Mak, T.W., Comeau, M.R., Croft, M., Girardin, S.E. and Philpott, D.J. (2011) Nucleotide oligomerization domain-containing proteins instruct $\mathrm{T}$ cell helper type 2 immunity through stromal activation. Proc. Natl. Acad. Sci. U.S.A. 108, 14896-14901.

22) Le Bourhis, L., Magalhaes, J.G., Selvanantham, T., Travassos, L.H., Geddes, K., Fritz, J.H., Viala, J., Tedin, K., Girardin, S.E. and Philpott, D.J. (2009) Role of Nod1 in mucosal dendritic cells during Salmonella pathogenicity island 1-independent Salmonella enterica serovar Typhimurium infection. Infect. Immun. 77, 4480-4486.

23) Kim, Y.G., Park, J.H., Reimer, T., Baker, D.P., Kawai, T., Kumar, H., Akira, S., Wobus, C. and Nunez, G. (2011) Viral infection augments Nod1/ 2 signaling to potentiate lethality associated with secondary bacterial infections. Cell Host Microbe 9, 496-507.

24) Kim, Y.G., Park, J.H., Shaw, M.H., Franchi, L., Inohara, N. and Nunez, G. (2008) The cytosolic sensors Nod1 and Nod2 are critical for bacterial recognition and host defense after exposure to toll-like receptor ligands. Immunity $\mathbf{2 8}, 246-257$.

25) Liew, F.Y., Xu, D., Brint, E.K. and O'Neill, L.A. (2005) Negative regulation of toll-like receptormediated immune responses. Nat. Rev. Immunol. 5, 446-458.

26) Petterson, T., Jendholm, J., Mansson, A., Bjartell, A., Riesbeck, K. and Cardell, L.O. (2011) Effects of NOD-like receptors in human B lymphocytes and crosstalk between NOD1/NOD2 and toll-like receptors. J. Leukoc. Biol. 89, 177-187.

27) Petterson, T., Mansson, A., Riesbeck, K. and Cardell, L.O. (2011) Nucleotide-binding and oligomerization domain-like receptors and retinoic acid inducible gene-like receptors in human tonsillar T lymphocytes. Immunology 133, 84-93.

28) Clarke, T.B., Davis, K.M., Lysenko, E.S., Zhou, A.Y., Yu, Y. and Weiser, J.N. (2010) Recognition of peptidoglycan from the microbiota by Nod1 
enhances systemic innate immunity. Nat. Med. 16, 228-231.

29) Hergott, C.B., Roche, A.M., Tamashiro, E., Clarke, T.B., Bailey, A.G., Laughlin, A., Bushman, F.D. and Weiser, J.N. (2016) Peptidoglycan from the gut microbiota governs the lifespan of circulating phagocytes at homeostasis. Blood 127, 24602471.

30) Natividad, J.M., Petit, V., Huang, X., de Palma, G., Jury, J., Sanz, Y., Philpott, D., Garcia Rodenas, C.L., McCoy, K.D. and Verdu, E.F. (2012) Commensal and probiotic bacteria influence intestinal barrier function and susceptibility to colitis in Nod1-/-; Nod2-/- mice. Inflamm. Bowel Dis. 18, 1434-1446.

31) Robertson, S.J., Zhou, J.Y., Geddes, K., Rubino, S.J., Cho, J.H., Girardin, S.E. and Philpott, D.J. (2013) Nod1 and Nod2 signaling does not alter the composition of intestinal bacterial communities at homeostasis. Gut Microbes 4, 222-231.

32) Amendola, A., Butera, A., Sanchez, M., Strober, W. and Boirivant, M. (2014) Nod2 deficiency is associated with an increased mucosal immunoregulatory response to commensal microorganisms. Mucosal Immunol. 7, 391-404.

33) Grubman, A., Kaparakis, M., Viala, J., Allison, C., Badea, L., Karrar, A., Boneca, I.G., Le Bourhis, L., Reeve, S., Smith, I.A., Hartland, E.L., Philpott, D.J. and Ferrero, R.L. (2010) The innate immune molecule, NOD1, regulates direct killing of Helicobacter pylori by antimicrobial peptides. Cell. Microbiol. 12, 626-639.

34) Watanabe, T., Asano, N., Kitani, A., Fuss, I.J. Chiba, T. and Strober, W. (2011) Activation of type I IFN signaling by NOD1 mediates mucosal host defense against Helicobacter pylori infection. Gut Microbes 2, 61-65.

35) Kim, J.G., Lee, S.J. and Kagnoff, M.F. (2004) Nod1 is an essential signal transducer in intestinal epithelial cells infected with bacteria that avoid recognition by toll-like receptors. Infect. Immun. 72, 1487-1495.

36) Hasegawa, M., Yamazaki, T., Kamada, N., Tawaratsumida, K., Kim, Y.G., Nunez, G. and Inohara, N. (2011) Nucleotide-binding oligomerization domain 1 mediates recognition of Clostridium difficile and induces neutrophil recruitment and protection against the pathogen. J. Immunol. 186, 4872-4880.

37) Kavathas, P.B., Boeras, C.M., Mulla, M.J. and Abrahams, V.M. (2013) Nod1, but not the ASC inflammasome, contributes to induction of IL1beta secretion in human trophoblasts after sensing of Chlamydia trachomatis. Mucosal Immunol. 6, 235-243.

38) Opitz, B., Forster, S., Hocke, A.C., Maass, M., Schmeck, B., Hippenstiel, S., Suttorp, N. and Krull, M. (2005) Nod1-mediated endothelial cell activation by Chlamydophila pneumoniae. Circ. Res. 96, 319-326.

39) Scott, M.J., Chen, C., Sun, Q. and Billiar, T.R. (2010) Hepatocytes express functional NOD1 and
NOD2 receptors: a role for NOD1 in hepatocyte $\mathrm{CC}$ and CXC chemokine production. J. Hepatol. 53, 693-701.

40) Stockinger, S., Reutterer, B., Schaljo, B., Schellack, C., Brunner, S., Materna, T., Yamamoto, M., Akira, S., Taniguchi, T., Murray, P.J., Muller, M. and Decker, T. (2004) IFN regulatory factor 3dependent induction of type I IFNs by intracellular bacteria is mediated by a TLR- and Nod2independent mechanism. J. Immunol. 173, 74167425 .

41) Hisamatsu, T., Suzuki, M. and Podolsky, D.K. (2003) Interferon-gamma augments CARD4/ NOD1 gene and protein expression through interferon regulatory factor- 1 in intestinal epithelial cells. J. Biol. Chem. 278, 32962-32968.

42) Fan, Y.H., Roy, S., Mukhopadhyay, R., Kapoor, A., Duggal, P., Wojcik, G.L., Pass, R.F. and AravBoger, R. (2016) Role of nucleotide-binding oligomerization domain 1 (NOD1) and its variants in human cytomegalovirus control in vitro and in vivo. Proc. Natl. Acad. Sci. U.S.A. 113, E7818-E7827.

43) Vegna, S., Gregoire, D., Moreau, M., Lassus, P., Durantel, D., Assenat, E., Hibner, U. and Simonin, Y. (2016) NOD1 participates in the innate immune response triggered by Hepatitis $\mathrm{C}$ virus polymerase. J. Virol. 90, 6022-6035.

44) Park, J.H., Kim, Y.G., McDonald, C., Kanneganti, T.D., Hasegawa, M., Body-Malapel, M., Inohara, N. and Nunez, G. (2007) RICK/RIP2 mediates innate immune responses induced through Nod1 and Nod2 but not TLRs. J. Immunol. 178, 23802386.

45) Park, J.H., Kim, Y.G., Shaw, M., Kanneganti, T.D., Fujimoto, Y., Fukase, K., Inohara, N. and Nunez, G. (2007) Nod1/RICK and TLR signaling regulate chemokine and antimicrobial innate immune responses in mesothelial cells. J. Immunol. 179, $514-521$.

46) Kobayashi, K., Inohara, N., Hernandez, L.D., Galan, J.E., Nunez, G., Janeway, C.A., Medzhitov, R. and Flavell, R.A. (2002) RICK/Rip2/CARDIAK mediates signalling for receptors of the innate and adaptive immune systems. Nature 416, 194-199.

47) Chin, A.I., Dempsey, P.W., Bruhn, K., Miller, J.F., $\mathrm{Xu}, \mathrm{Y}$. and Cheng, G. (2002) Involvement of receptor-interacting protein 2 in innate and adaptive immune responses. Nature 416, 190-194.

48) Lu, C., Wang, A., Dorsch, M., Tian, J., Nagashima, K., Coyle, A.J., Jaffee, B., Ocain, T.D. and Xu, Y. (2005) Participation of Rip2 in lipopolysaccharide signaling is independent of its kinase activity. J. Biol. Chem. 280, 16278-16283.

49) Hall, H.T., Wilhelm, M.T., Saibil, S.D., Mak, T.W., Flavell, R.A. and Ohashi, P.S. (2008) RIP2 contributes to Nod signaling but is not essential for $\mathrm{T}$ cell proliferation, $\mathrm{T}$ helper differentiation or TLR responses. Eur. J. Immunol. 38, 64-72.

50) Bertrand, M.J., Doiron, K., Labbe, K., Korneluk, R.G., Barker, P.A. and Saleh, M. (2009) Cellular inhibitors of apoptosis cIAP1 and cIAP2 are 
required for innate immunity signaling by the pattern recognition receptors NOD1 and NOD2. Immunity 30, 789-801.

51) Yang, Y., Yin, C., Pandey, A., Abbott, D., Sassetti, C. and Kelliher, M.A. (2007) NOD2 pathway activation by MDP or Mycobacterium tuberculosis infection involves the stable polyubiquitination of Rip2. J. Biol. Chem. 282, 36223-36229.

52) Watanabe, T., Asano, N., Meng, G., Yamashita, K., Arai, Y., Sakurai, T., Kudo, M., Fuss, I.J., Kitani, A., Shimosegawa, T., Chiba, T. and Strober, W. (2014) NOD2 downregulates colonic inflammation by IRF4-mediated inhibition of K63-linked polyubiquitination of RICK and TRAF6. Mucosal Immunol. 7, 1312-1325.

53) Tigno-Aranjuez, J.T., Asara, J.M. and Abbott, D.W. (2010) Inhibition of RIP2's tyrosine kinase activity limits NOD2-driven cytokine responses. Genes Dev. 24, 2666-2677.

54) Damgaard, R.B., Fiil, B.K., Speckmann, C., Yabal, M., zur Stadt, U., Bekker-Jensen, S., Jost, P.J., Ehl, S., Mailand, N. and Gyrd-Hansen, M. (2013) Disease-causing mutations in the XIAP BIR2 domain impair NOD2-dependent immune signalling. EMBO Mol. Med. 5, 1278-1295.

55) Damgaard, R.B., Nachbur, U., Yabal, M., Wong, W.W., Fiil, B.K., Kastirr, M., Rieser, E., Rickard, J.A., Bankovacki, A., Peschel, C., Ruland, J., Bekker-Jensen, S., Mailand, N., Kaufmann, T., Strasser, A., Walczak, H., Silke, J., Jost, P.J. and Gyrd-Hansen, M. (2012) The ubiquitin ligase XIAP recruits LUBAC for NOD2 signaling in inflammation and innate immunity. Mol. Cell 46, 746-758.

56) Tokunaga, F., Sakata, S., Saeki, Y., Satomi, Y., Kirisako, T., Kamei, K., Nakagawa, T., Kato, M., Murata, S., Yamaoka, S., Yamamoto, M., Akira, S., Takao, T., Tanaka, K. and Iwai, K. (2009) Involvement of linear polyubiquitylation of NEMO in NF-kappaB activation. Nat. Cell Biol. 11, 123-132.

57) Yang, S., Wang, B., Humphries, F., Jackson, R., Healy, M.E., Bergin, R., Aviello, G., Hall, B., McNamara, D., Darby, T., Quinlan, A., Shanahan, F., Melgar, S., Fallon, P.G. and Moynagh, P.N. (2013) Pellino3 ubiquitinates RIP2 and mediates Nod2-induced signaling and protective effects in colitis. Nat. Immunol. 14, 927-936.

58) Tao, M., Scacheri, P.C., Marinis, J.M., Harhaj, E.W., Matesic, L.E. and Abbott, D.W. (2009) ITCH K63-ubiquitinates the NOD2 binding protein, RIP2, to influence inflammatory signaling pathways. Curr. Biol. 19, 1255-1263.

59) Hrdinka, M., Fiil, B.K., Zucca, M., Leske, D., Bagola, K., Yabal, M., Elliott, P.R., Damgaard, R.B., Komander, D., Jost, P.J. and Gyrd-Hansen, M. (2016) CYLD limits Lys63- and Met1-linked ubiquitin at receptor complexes to regulate innate immune signaling. Cell Reports 14, 2846-2858.

60) Draber, P., Kupka, S., Reichert, M., Draberova, H., Lafont, E., de Miguel, D., Spilgies, L., Surinova, S., Taraborrelli, L., Hartwig, T., Rieser, E.,
Martino, L., Rittinger, K. and Walczak, H. (2015) LUBAC-recruited CYLD and A20 regulate gene activation and cell death by exerting opposing effects on linear ubiquitin in signaling complexes. Cell Reports 13, 2258-2272.

61) Hitotsumatsu, O., Ahmad, R.C., Tavares, R., Wang, M., Philpott, D., Turer, E.E., Lee, B.L., Shiffin, N., Advincula, R., Malynn, B.A., Werts, C. and Ma, A. (2008) The ubiquitin-editing enzyme A20 restricts nucleotide-binding oligomerization domain containing 2-triggered signals. Immunity 28, 381-390.

62) Marinis, J.M., Homer, C.R., McDonald, C. and Abbott, D.W. (2011) A novel motif in the Crohn's disease susceptibility protein, NOD2, allows TRAF4 to down-regulate innate immune responses. J. Biol. Chem. 286, 1938-1950.

63) Marinis, J.M., Hutti, J.E., Homer, C.R., Cobb, B.A., Cantley, L.C., McDonald, C. and Abbott, D.W. (2012) IkappaB kinase alpha phosphorylation of TRAF4 downregulates innate immune signaling. Mol. Cell. Biol. 32, 2479-2489.

64) Correa, R.G., Khan, P.M., Askari, N., Zhai, D., Gerlic, M., Brown, B., Magnuson, G., Spreafico, R., Albani, S., Sergienko, E., Diaz, P.W., Roth, G.P. and Reed, J.C. (2011) Discovery and characterization of 2-aminobenzimidazole derivatives as selective NOD1 inhibitors. Chem. Biol. 18, 825-832.

65) Honda, K., Yanai, H., Takaoka, A. and Taniguchi, T. (2005) Regulation of the type I IFN induction: a current view. Int. Immunol. 17, 1367-1378.

66) Christensen, J.E., de Lemos, C., Moos, T., Christensen, J.P. and Thomsen, A.R. (2006) CXCL10 is the key ligand for CXCR3 on CD8+ effector $\mathrm{T}$ cells involved in immune surveillance of the lymphocytic choriomeningitis virus-infected central nervous system. J. Immunol. 176, 42354243.

67) Hsieh, M.F., Lai, S.L., Chen, J.P., Sung, J.M., Lin, Y.L., Wu-Hsieh, B.A., Gerard, C., Luster, A. and Liao, F. (2006) Both CXCR3 and CXCL10/IFNinducible protein 10 are required for resistance to primary infection by dengue virus. J. Immunol. 177, 1855-1863.

68) Romagnani, P., Maggi, L., Mazzinghi, B., Cosmi, L., Lasagni, L., Liotta, F., Lazzeri, E., Angeli, R., Rotondi, M., Fili, L., Parronchi, P., Serio, M., Maggi, E., Romagnani, S. and Annunziato, F. (2005) CXCR3-mediated opposite effects of CXCL10 and CXCL4 on TH1 or TH2 cytokine production. J. Allergy Clin. Immunol. 116, 13721379 .

69) Hasegawa, M., Fujimoto, Y., Lucas, P.C., Nakano, H., Fukase, K., Nunez, G. and Inohara, N. (2008) A critical role of RICK/RIP2 polyubiquitination in Nod-induced NF-kappaB activation. EMBO J. 27, 373-383.

70) Honda, K., Yanai, H., Negishi, H., Asagiri, M., Sato, M., Mizutani, T., Shimada, N., Ohba, Y., Takaoka, A., Yoshida, N. and Taniguchi, T. (2005) IRF-7 is the master regulator of type-I 
interferon-dependent immune responses. Nature 434, 772-777.

71) Honda, K., Ohba, Y., Yanai, H., Negishi, H., Mizutani, T., Takaoka, A., Taya, C. and Taniguchi, T. (2005) Spatiotemporal regulation of MyD88-IRF-7 signalling for robust type-I interferon induction. Nature 434, 1035-1040.

72) Hacker, H., Redecke, V., Blagoev, B., Kratchmarova, I., Hsu, L.C., Wang, G.G., Kamps, M.P., Raz, E., Wagner, H., Hacker, G., Mann, M. and Karin, M. (2006) Specificity in Toll-like receptor signalling through distinct effector functions of TRAF3 and TRAF6. Nature 439, 204-207.

73) Mizushima, N., Levine, B., Cuervo, A.M. and Klionsky, D.J. (2008) Autophagy fights disease through cellular self-digestion. Nature 451, 10691075.

74) Travassos, L.H., Carneiro, L.A., Ramjeet, M., Hussey, S., Kim, Y.G., Magalhaes, J.G., Yuan, L., Soares, F., Chea, E., Le Bourhis, L., Boneca, I.G., Allaoui, A., Jones, N.L., Nunez, G., Girardin, S.E. and Philpott, D.J. (2010) Nod1 and Nod2 direct autophagy by recruiting ATG16L1 to the plasma membrane at the site of bacterial entry. Nat. Immunol. 11, 55-62.

75) Sorbara, M.T., Ellison, L.K., Ramjeet, M., Travassos, L.H., Jones, N.L., Girardin, S.E. and Philpott, D.J. (2013) The protein ATG16L1 suppresses inflammatory cytokines induced by the intracellular sensors Nod1 and Nod2 in an autophagy-independent manner. Immunity 39 858-873.

76) Celli, J. and Tsolis, R.M. (2015) Bacteria, the endoplasmic reticulum and the unfolded protein response: friends or foes? Nat. Rev. Microbiol. 13, $71-82$.

77) Keestra-Gounder, A.M., Byndloss, M.X., Seyffert, N., Young, B.M., Chavez-Arroyo, A., Tsai, A.Y., Cevallos, S.A., Winter, M.G., Pham, O.H., Tiffany, C.R., de Jong, M.F., Kerrinnes, T., Ravindran, R., Luciw, P.A., McSorley, S.J., Baumler, A.J. and Tsolis, R.M. (2016) NOD1 and NOD2 signalling links ER stress with inflammation. Nature 532, 394-397.

78) Hatakeyama, M. (2014) Helicobacter pylori CagA and gastric cancer: a paradigm for hit-and-run carcinogenesis. Cell Host Microbe 15, 306-316.

79) Fischer, W. (2011) Assembly and molecular mode of action of the Helicobacter pylori Cag type IV secretion apparatus. FEBS J. 278, 1203-1212.

80) Kaparakis, M., Turnbull, L., Carneiro, L., Firth, S., Coleman, H.A., Parkington, H.C., Le Bourhis, L., Karrar, A., Viala, J., Mak, J., Hutton, M.L., Davies, J.K., Crack, P.J., Hertzog, P.J., Philpott, D.J., Girardin, S.E., Whitchurch, C.B. and Ferrero, R.L. (2010) Bacterial membrane vesicles deliver peptidoglycan to NOD1 in epithelial cells. Cell Microbiol. 12, 372-385.

81) D'Elios, M.M., Manghetti, M., De Carli, M., Costa, F., Baldari, C.T., Burroni, D., Telford, J.L., Romagnani, S. and Del Prete, G. (1997) T helper
1 effector cells specific for Helicobacter pylori in the gastric antrum of patients with peptic ulcer disease. J. Immunol. 158, 962-967.

82) Itoh, T., Wakatsuki, Y., Yoshida, M., Usui, T., Matsunaga, Y., Kaneko, S., Chiba, T. and Kita, T. (1999) The vast majority of gastric T cells are polarized to produce $\mathrm{T}$ helper 1 type cytokines upon antigenic stimulation despite the absence of Helicobacter pylori infection. J. Gastroenterol. 34, 560-570.

83) Garhart, C.A., Heinzel, F.P., Czinn, S.J. and Nedrud, J.G. (2003) Vaccine-induced reduction of Helicobacter pylori colonization in mice is interleukin-12 dependent but gamma interferon and inducible nitric oxide synthase independent. Infect. Immun. 71, 910-921.

84) Ferrero, R.L. (2005) Innate immune recognition of the extracellular mucosal pathogen, Helicobacter pylori. Mol. Immunol. 42, 879-885.

85) Andersen-Nissen, E., Smith, K.D., Strobe, K.L., Barrett, S.L., Cookson, B.T., Logan, S.M. and Aderem, A. (2005) Evasion of Toll-like receptor 5 by flagellated bacteria. Proc. Natl. Acad. Sci. U.S.A. 102, 9247-9252.

86) Eck, M., Schmausser, B., Scheller, K., Toksoy, A., Kraus, M., Menzel, T., Muller-Hermelink, H.K. and Gillitzer, R. (2000) CXC chemokines Gro(alpha)/IL-8 and IP-10/MIG in Helicobacter pylori gastritis. Clin. Exp. Immunol. 122, 192199.

87) Allison, C.C., Ferrand, J., McLeod, L., Hassan, M., Kaparakis-Liaskos, M., Grubman, A., Bhathal, P.S., Dev, A., Sievert, W., Jenkins, B.J. and Ferrero, R.L. (2013) Nucleotide oligomerization domain 1 enhances IFN-gamma signaling in gastric epithelial cells during Helicobacter pylori infection and exacerbates disease severity. J. Immunol. 190, 3706-3715.

88) Hirata, Y., Ohmae, T., Shibata, W., Maeda, S., Ogura, K., Yoshida, H., Kawabe, T. and Omata, M. (2006) MyD88 and TNF receptor-associated factor 6 are critical signal transducers in Helicobacter pylori-infected human epithelial cells. J. Immunol. 176, 3796-3803.

89) Allison, C.C., Kufer, T.A., Kremmer, E., Kaparakis, M. and Ferrero, R.L. (2009) Helicobacter pylori induces MAPK phosphorylation and AP-1 activation via a NOD1-dependent mechanism. J. Immunol. 183, 8099-8109.

90) Suarez, G., Romero-Gallo, J., Piazuelo, M.B., Wang, G., Maier, R.J., Forsberg, L.S., Azadi, P., Gomez, M.A., Correa, P. and Peek, R.M. Jr. (2015) Modification of Helicobacter pylori peptidoglycan enhances NOD1 activation and promotes cancer of the stomach. Cancer Res. 75, 1749-1759.

91) Camilo, V., Barros, R., Sousa, S., Magalhaes, A.M., Lopes, T., Mario Santos, A., Pereira, T., Figueiredo, C., David, L. and Almeida, R. (2012) Helicobacter pylori and the BMP pathway regulate CDX2 and SOX2 expression in gastric cells. Carcinogenesis 33, 1985-1992. 
92) Cosen-Binker, L.I. and Gaisano, H.Y. (2007) Recent insights into the cellular mechanisms of acute pancreatitis. Can. J. Gastroenterol. 21, 19-24.

93) Lankisch, P.G., Apte, M. and Banks, P.A. (2015) Acute pancreatitis. Lancet 386, 85-96.

94) Braganza, J.M., Lee, S.H., McCloy, R.F. and McMahon, M.J. (2011) Chronic pancreatitis. Lancet 377, 1184-1197.

95) Frossard, J.L., Steer, M.L. and Pastor, C.M. (2008) Acute pancreatitis. Lancet 371, 143-152.

96) Logsdon, C.D. and Ji, B. (2013) The role of protein synthesis and digestive enzymes in acinar cell injury. Nat. Rev. Gastroenterol. Hepatol. 10, $362-370$.

97) Saluja, A.K., Lerch, M.M., Phillips, P.A. and Dudeja, V. (2007) Why does pancreatic overstimulation cause pancreatitis? Annu. Rev. Physiol. 69, 249-269.

98) Whitcomb, D.C. (2010) Genetic aspects of pancreatitis. Annu. Rev. Med. 61, 413-424.

99) Dawra, R., Sah, R.P., Dudeja, V., Rishi, L., Talukdar, R., Garg, P. and Saluja, A.K. (2011) Intra-acinar trypsinogen activation mediates early stages of pancreatic injury but not inflammation in mice with acute pancreatitis. Gastroenterology 141, 2210-2217 e2.

100) Sah, R.P., Dudeja, V., Dawra, R.K. and Saluja, A.K. (2013) Cerulein-induced chronic pancreatitis does not require intra-acinar activation of trypsinogen in mice. Gastroenterology 144, 1076-1085 $\mathrm{e} 2$.

101) Ji, B. and Logsdon, C.D. (2011) Digesting new information about the role of trypsin in pancreatitis. Gastroenterology 141, 1972-1975.

102) Medich, D.S., Lee, T.K., Melhem, M.F., Rowe, M.I., Schraut, W.H. and Lee, K.K. (1993) Pathogenesis of pancreatic sepsis. Am. J. Surg. 165, 46-50; discussion $51-2$.

103) Gianotti, L., Munda, R., Alexander, J.W., Tchervenkov, J.I. and Babcock, G.F. (1993) Bacterial translocation: a potential source for infection in acute pancreatitis. Pancreas 8, 551558.

104) Runkel, N.S., Moody, F.G., Smith, G.S., Rodriguez, L.F., LaRocco, M.T. and Miller, T.A. (1991) The role of the gut in the development of sepsis in acute pancreatitis. J. Surg. Res. 51, 18-23.

105) Mithofer, K., Fernandez-del Castillo, C., Ferraro, M.J., Lewandrowski, K., Rattner, D.W. and Warshaw, A.L. (1996) Antibiotic treatment improves survival in experimental acute necrotizing pancreatitis. Gastroenterology 110, 232-240.

106) Fritz, S., Hartwig, W., Lehmann, R., WillSchweiger, K., Kommerell, M., Hackert, T., Schneider, L., Buchler, M.W. and Werner, J. (2008) Prophylactic antibiotic treatment is superior to therapy on-demand in experimental necrotising pancreatitis. Crit. Care 12, R141.

107) Foitzik, T., Fernandez-del Castillo, C., Ferraro, M.J., Mithofer, K., Rattner, D.W. and Warshaw, A.L. (1995) Pathogenesis and prevention of early pancreatic infection in experimental acute necrotizing pancreatitis. Ann. Surg. 222, 179-185.

108) Li, Q., Wang, C., Tang, C., He, Q., Li, N. and Li, J. (2013) Bacteremia in patients with acute pancreatitis as revealed by $16 \mathrm{~S}$ ribosomal RNA genebased techniques*. Crit. Care Med. 41, 19381950.

109) Yasuda, T., Ueda, T., Shinzeki, M., Sawa, H., Nakajima, T., Takeyama, Y. and Kuroda, Y. (2007) Increase of high-mobility group box chromosomal protein 1 in blood and injured organs in experimental severe acute pancreatitis. Pancreas 34, 487-488.

110) Yasuda, T., Ueda, T., Takeyama, Y., Shinzeki, M., Sawa, H., Nakajima, T., Ajiki, T., Fujino, Y., Suzuki, Y. and Kuroda, Y. (2006) Significant increase of serum high-mobility group box chromosomal protein 1 levels in patients with severe acute pancreatitis. Pancreas 33, 359-363.

111) Kono, H. and Rock, K.L. (2008) How dying cells alert the immune system to danger. Nat. Rev. Immunol. 8, 279-289.

112) Satoh, A., Gukovskaya, A.S., Nieto, J.M., Cheng, J.H., Gukovsky, I., Reeve, J.R. Jr., Shimosegawa, T. and Pandol, S.J. (2004) PKC-delta and -epsilon regulate NF-kappaB activation induced by cholecystokinin and TNF-alpha in pancreatic acinar cells. Am. J. Physiol. Gastrointest. Liver Physiol. 287, G582-G591.

113) Yu, J.H., Kim, K.H. and Kim, H. (2006) Suppression of IL-1beta expression by the Jak 2 inhibitor AG490 in cerulein-stimulated pancreatic acinar cells. Biochem. Pharmacol. 72, 1555-1562.

114) Deshmane, S.L., Kremlev, S., Amini, S. and Sawaya, B.E. (2009) Monocyte chemoattractant protein-1 (MCP-1): an overview. J. Interferon Cytokine Res. 29, 313-326.

115) Fichtner-Feigl, S., Strober, W., Geissler, E.K. and Schlitt, H.J. (2008) Cytokines mediating the induction of chronic colitis and colitis-associated fibrosis. Mucosal Immunol. 1 (Suppl 1), S24-S27.

116) McHedlidze, T., Waldner, M., Zopf, S., Walker, J., Rankin, A.L., Schuchmann, M., Voehringer, D., McKenzie, A.N., Neurath, M.F., Pflanz, S. and Wirtz, S. (2013) Interleukin-33-dependent innate lymphoid cells mediate hepatic fibrosis. Immunity 39, 357-371.

117) Cayrol, C. and Girard, J.P. (2014) IL-33: an alarmin cytokine with crucial roles in innate immunity, inflammation and allergy. Curr. Opin. Immunol. 31C, 31-37.

118) Mancuso, G., Midiri, A., Biondo, C., Beninati, C., Zummo, S., Galbo, R., Tomasello, F., Gambuzza, M., Macri, G., Ruggeri, A., Leanderson, T. and Teti, G. (2007) Type I IFN signaling is crucial for host resistance against different species of pathogenic bacteria. J. Immunol. 178, 3126-3133.

(Received May 13, 2017; accepted May 31, 2017) 


\section{Profile}

Tomohiro Watanabe graduated from Kyoto University School of Medicine in 1993. He trained in Internal Medicine and Gastroenterology at Kobe City General Hospital. He started research on liver immunology at Department of Gastroenterology and Hepatology, Kyoto University Graduate School of Medicine (Prof. Tsutomu Chiba) and obtained a Ph.D. in 2002. He worked as a postdoctoral fellow at Mucosal Immunity Section, Laboratory of Host Defenses, National Institutes of Health (Dr. Warren Strober) and studied the immuno-pathogenesis of inflammatory bowel diseases and Helicobacter pylori-associated gastritis between 2003 and 2006. He then moved back to Department of Gastroenterology and Hepatology, Kyoto University Graduate School of Medicine (Prof. Tsutomu Chiba) as an assistant professor and then was assigned as an associate professor

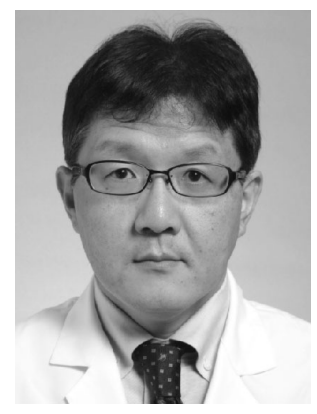
in 2011. In 2016, He became an associate professor at Department of Gastroenterology and Hepatology, Kindai University Faculty of Medicine (Prof. Masatoshi Kudo). He has been studying the immuno-pathogenesis of gastrointestinal disorders including inflammatory bowel diseases, Helicobacter pylori-associated gastritis, pancreatitis, and IgG4-related diseases. 